\title{
Unambiguous evidence of old soil carbon in grass biosilica particles
}

\author{
Paul E. Reyerson ${ }^{1,2, a}$, Anne Alexandre ${ }^{3}$, Araks Harutyunyan ${ }^{1}$, Remi Corbineau ${ }^{3}$, Hector A. Martinez De La Torre ${ }^{1}$, \\ Franz Badeck $^{4}$, Luigi Cattivelli ${ }^{4}$, and Guaciara M. Santos ${ }^{1}$ \\ ${ }^{1}$ Earth System Science, University of California, Irvine, USA \\ ${ }^{2}$ Department of Botany, University of Wisconsin-Madison, USA \\ ${ }^{3}$ Aix Marseille Université, CNRS, IRD, CEREGE UM34, 13545 Aix-en-Provence CEDEX 4, France \\ ${ }^{4}$ Consiglio per la Ricerca in Agricoltura e l'analisi dell'economis agraria - Genomics Research Centre, \\ Fiorenzuola d'Arda, Italy \\ ${ }^{\mathrm{a}}$ current address: Department of Geography and Earth Science, University of Wisconsin-La Crosse, USA
}

Correspondence to: Guaciara M. Santos (gdossant@uci.edu)

Received: 19 June 2015 - Published in Biogeosciences Discuss.: 17 September 2015

Revised: 27 January 2016 - Accepted: 8 February 2016 - Published: 1 March 2016

\begin{abstract}
Plant biosilica particles (phytoliths) contain small amounts of carbon called phytC. Based on the assumptions that phytC is of photosynthetic origin and a closed system, claims were recently made that phytoliths from several agriculturally important monocotyledonous species play a significant role in atmospheric $\mathrm{CO}_{2}$ sequestration. However, anomalous phytC radiocarbon $\left({ }^{14} \mathrm{C}\right)$ dates suggested contributions from a non-photosynthetic source to phytC. Here we address this non-photosynthetic source hypothesis using comparative isotopic measurements $\left({ }^{14} \mathrm{C}\right.$ and $\left.\delta^{13} \mathrm{C}\right)$ of phytC, plant tissues, atmospheric $\mathrm{CO}_{2}$, and soil organic matter. State-of-the-art methods assured phytolith purity, while sequential stepwise-combustion revealed complex chemicalthermal decomposability properties of phytC. Although photosynthesis is the main source of carbon in plant tissue, it was found that phytC is partially derived from soil carbon that can be several thousand years old. The fact that phytC is not uniquely constituted of photosynthetic $\mathrm{C}$ limits the usefulness of phytC either as a dating tool or as a significant sink of atmospheric $\mathrm{CO}_{2}$. It additionally calls for further experiments to investigate how SOM-derived $\mathrm{C}$ is accessible to roots and accumulates in plant biosilica, for a better understanding of the mechanistic processes underlying the silicon biomineralization process in higher plants.
\end{abstract}

\section{Introduction}

Silicon ( $\mathrm{Si}$ ) is the most abundant element in the Earth's crust and is widely recycled by higher plants. Si is acquired by roots from soils and precipitated in or between the cells as micrometric hydrous amorphous biosilica particles called phytoliths. Phytolith abundances range from $<1 \%$ of dry weight (dwt) in many plants to several \% dwt in grasses that are Si-accumulators (Geis, 1973; Runge, 1999; Webb and Longstaffe, 2000; Raven, 2003). Phytoliths contain small amounts of carbon $(\mathrm{C})$ occluded during silica precipitation (Alexandre et al., 2015), commonly termed as phytC or phytOC and assumed to be of photosynthetic origin (Carter 2009; Piperno, 2006) (Fig. 1a). Thus, phytC isotopic signatures $\left(\delta^{13} \mathrm{C}\right.$ and $\left.{ }^{14} \mathrm{C}\right)$ obtained from buried soils and sedimentary archives have been interpreted in terms of paleoenvironmental changes (Kelly et al., 1991; Carter, 2009; McInerney et al., 2011), or used as a dating tool (McClaran and Umlauf, 2000; Piperno and Stothert, 2003; Parr and Sullivan, 2005; Piperno, 2006).

Motivated by anthropogenic emissions of carbon dioxide $\left(\mathrm{CO}_{2}\right)$ (Mauna Loa Observatory; NOAA-ESRL data at http://www.esrl.noaa.gov/) and their direct association with climate change, a set of recent studies has advanced the idea that many monocotyledonous crop species (bamboo, sugarcane, maize, rice, etc.) as well as grasslands in general (among the largest ecosystems in the world - Suttie et al., 2005) may play a significant role in $C$ sequestration through a newly evidenced mechanism: $\mathrm{CO}_{2}$ biosequestration in grass 


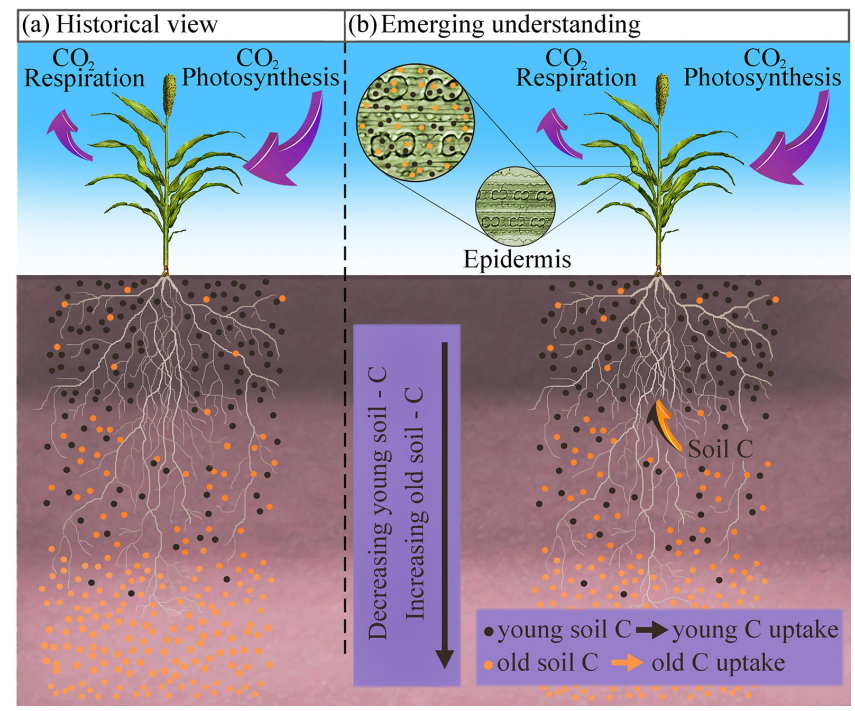

Figure 1. Sketch of (a) the conventional hypothesis of plant $\mathrm{C}$ occlusion during silica precipitation based solely on atmospheric $\mathrm{CO}_{2}$ as a source, and (b) the emerging hypothesis of a dual origin (atmospheric $\mathrm{CO}_{2}$ and $\mathrm{SOM}$ ) for plant $\mathrm{C}$ (and phytC). Young and old soil $\mathrm{C}$ distributed in leaf epidermis (green tissue) and phytoliths (illustrated by the bilobate type shape outlined in black) are represented by black and orange dots, respectively, in the microscope diagram.

biosilica particles (Parr and Sullivan, 2005, 2011; Parr et al., 2009, 2010; Song et al., 2013, 2014; Toma et al., 2013). If correct, encapsulated atmospheric $\mathrm{CO}_{2}$ can be slowly and steadily accumulated in soils, with turnover times of the order of several hundreds to thousands of years (Parr and Sullivan, 2005). Selective use of silica accumulator crops could further enhance this sequestration mechanism (Song et al., 2013).

However, the validity of these interpretations has recently been challenged. First, attempts to properly calibrate the geochemical signals borne by phytC were inconclusive (Wilding, 1967; Kelly et al., 1991; McClaran and Umlauf, 2000; Smith and White, 2004; Webb and Longstaffe, 2010). Second, differences in the efficiency of phytolith extraction protocols may have contributed to inconsistencies and overestimations in phytC quantification (from 0.1 to $20 \%$ of phytolith $\mathrm{dwt}$ ) (Corbineau et al., 2013 and references therein, Song et al., 2014 and references therein). Third, systematic offsets of phytC ${ }^{14} \mathrm{C}$ ages relative to the ${ }^{14} \mathrm{C}$ ages of the plant tissues from which phytoliths originate have been published (Santos et al., 2010, 2012a, b, 2016; Sullivan and Parr, 2013; Yin et al., 2014; Piperno, 2016). These offsets can be as large as hundreds to several thousands of years, regardless of the chemical protocol used for phytolith extractions, indicating the presence of a secondary contributor of $\mathrm{C}$ to phytC. Together, these observations led to the hypothesis that a whole or a fraction of phytC may come from old soil C (Santos et al., 2012a) (Fig. 1b). Previous analyses of macro- molecules embedded in phytoliths suggested a variety of organic molecules (Bauer et al., 2011 and references therein), but there is no direct evidence that they are solely synthesized by the plant. Moreover, a recent Nano Secondary Ion Mass Spectrometry (NanoSIMS) investigation of phytC distribution in the silica structure suggests that a significant part of phytC can be lost at the very first stage of phytolith dissolution (Alexandre et al., 2015), thus dissociating the concept of phytC protection from phytolith stability.

Therefore, if the soil $\mathrm{C}$ to phytC hypothesis is definitively confirmed, it casts doubt on the efficiency of paleoenvironmental reconstructions based on phytC as a proxy of plant $\mathrm{C}$, and raises questions regarding the present estimates of crop and grasslands phytolith efficiency in sequestering atmospheric $\mathrm{CO}_{2}$, as well as its assessment of long-term stabilization in soils based on fossil phytolith ${ }^{14} \mathrm{C}$ dating (decades versus hundreds, or thousands of years, as suggested by Parr and Sullivan, 2005). Additionally, confirmation of a dual origin (soil organic matter (SOM) and photosynthetic) of phytC would open new questions regarding plant-soil interactions and SOM recycling, relevant for our understanding of the role of terrestrial ecosystems in the $\mathrm{C}$ cycle.

To unequivocally establish that a fraction of phytC is indeed from soils, a robust data set is produced here by considering and ruling out all other factors that can possibly bias the isotopic signatures of phytC. We reassess the old soil $\mathrm{C}$ contribution to phytC hypothesis (Santos et al., 2012a) on the basis of $>200$ isotopic results $\left(\delta^{13} \mathrm{C}\right.$ and/or $\left.{ }^{14} \mathrm{C}\right)$ of phytoliths and associated materials (grass tissues, SOM fractions, amendments and hydroponic solutions, $\mathrm{CO}_{2}$ respired from substrates or extracted from air). Pure phytolith concentrates were acquired from sets of above- and below-ground C manipulation experiments. Phytolith concentrates were extracted using several protocols with different degrees of aggressiveness (Corbineau et al., 2013) in four different laboratories. Cutting-edge techniques assured phytolith purity, and multiple analyses of carbon isotope reference materials assured high quality and reproducibility of the isotopic results. Furthermore, to establish a link between phytC heterogeneity in the sense of molecular complexity and resistance to oxidation (labile vs. recalcitrant), we subjected duplicates of pure phytolith extracts to thermal treatments. The multimethodology approach used in this study allows us to completely address: (a) the anomalous ${ }^{14} \mathrm{C}$ results associated with phytC in the literature, (b) the implications of a soil $\mathrm{C}$ contribution to phytC for ${ }^{14} \mathrm{C}$ geochronology dates, and (c) the shortcomings of using phytC as an atmospheric $\mathrm{CO}_{2}$ sink.

\section{Material and methods}

\subsection{Samples}

Our experimental design is based on a two-step process. First, in order to evidence whether the ${ }^{14} \mathrm{C}$ signatures of 
phytC are solely of photosynthetic origin, we select samples from known-year specimens, and compare plant material grown under normal atmospheric $\mathrm{CO}_{2}$ conditions to the artificially altered plant $\mathrm{C}$ isotope content of photosynthetically assimilated depleted- ${ }^{14} \mathrm{CO}_{2}$ from Free Air Carbon Enrichment (FACE) experiments (Sect. 2.1.1). Second, we seek to establish a causal connection between soil $\mathrm{C}$ and phytC by selecting samples from plant material grown under normal atmospheric $\mathrm{CO}_{2}$ conditions, but altered substrate carbon pools (Sect. 2.1.2). In both cases phytC and an array of samples associated with it were selected.

\subsubsection{Above-ground C manipulation experiments}

The FACE experiments exposed the plants to elevated atmospheric $\mathrm{CO}_{2}$ concentrations by continuously releasing $\mathrm{CO}_{2}$ through jets from tubes installed in the surroundings and within the enclosures of the cultivation plots. Target mixing ratios of atmospheric and geologic $\mathrm{CO}_{2}$ were maintained on plots until leaves were senescent and/or ready for harvesting.

Two grass species (Sorghum bicolor and Triticum durum) were grown in two FACE experiments, respectively: at the Maricopa Agricultural Center (University of Arizona, USA) in 1998-1999 (Ottman et al., 2001), and at the Genomics Research Centre of CREA (Consiglio per la ricerca in agricoltura e l'analisi dell'economia agraria) in Fiorenzuola d'Arda, Italy, in 2011-2012 (Badeck et al., 2012; http://centrodigenomica.entecra.it/research/ durumFACE). For each experiment, a plot cultivated under ambient atmospheric $\mathrm{CO}_{2}$ was compared to a plot cultivated under atmosphere enriched by 160-200 ppm in fossil hydrothermal $\mathrm{CO}_{2}$, and therefore free of ${ }^{14} \mathrm{C}$ (Leavitt, 1994; Ottman et al., 2001; Badeck et al., 2012). In terms of stable isotopic labeling, at the sorghum site the enriched $\mathrm{CO}_{2}$ had a $\delta^{13} \mathrm{C}$ value of $-40 \%$ from 1995 to 1998 . This stronger isotopic label was obtained from a mixture of natural $\mathrm{CO}_{2}$ from the Springerville, AZ, USA geologic wells with $15 \%$ petroleum-derived $\mathrm{CO}_{2}$. During 1998-1999 only fossil hydrothermal $\mathrm{CO}_{2}$ was used $\left({ }^{13} \mathrm{C}=-4.36 \%\right.$ ), while the background air $\delta^{13} \mathrm{C}$ was $-8 \%$ (Leavitt et al., 2001). At the durum wheat site, the commercial fossil $\mathrm{CO}_{2}$ from the Rapolano Terme, Poggio S. Cecilia (Tuscany) well had a $\delta^{13} \mathrm{C}$ of $-6.07 \%$, which was slightly positive compared to the ambient $\mathrm{CO}_{2}$ value of $-8 \%$.

Two samples of mixed stems and leaves $(\sim 100 \mathrm{~g})$ were obtained from the sorghum site, while four separated samples (300-400 g each) of stems and leaves were collected at the durum wheat site. Eight soil samples $(\sim 5 \mathrm{~g}$ each $)$ collected from the furrows of the sorghum plots at depths of 0 $15,15-30,30-45$, and $45-60 \mathrm{~cm}$ were also obtained from the archives of the Laboratory of Tree-Ring Research, University of Arizona, USA. While two soil samples were collected from the ongoing durum wheat experimental plots at a depth of $0-15 \mathrm{~cm}(\sim 15 \mathrm{~g}$ each $)$ during plant biomass harvesting.
To determine the precise ${ }^{14} \mathrm{C}$ activity of the plant materials, radiocarbon measurements were conducted before the phytolith extractions started. Since the commercial $\mathrm{CO}_{2}$ used in both FACE enrichment sites was from a fossil source, its ${ }^{14} \mathrm{C}$ signature as fraction of modern carbon (FmC or $\mathrm{Fm}^{14} \mathrm{C}$; Stuiver and Polach, 1977) was close to zero. Therefore, the ${ }^{14} \mathrm{C}$ signature of the enriched $\mathrm{CO}_{2}$ was highly depleted compared to ambient air, and the plant tissues were tagged accordingly. Radiocarbon signatures of the plant tissue yielded $\mathrm{Fm}{ }^{14} \mathrm{C}$ values of $0.640\left(\sim 3.6 \mathrm{kyr} \mathrm{BP} ;{ }^{14} \mathrm{C}\right.$ years before present or 1950; UCIAMS53273 and 53274; Table S1 in Supplement) and 0.556 ( $4.7 \mathrm{kyr}$ BP; UCIAMS109000 and 109001; Table S2 in Supplement) at the sorghum and durum sites, respectively. Alternatively, plant tissue from ambient $\mathrm{CO}_{2}$ plots was expected to yield the prescribed atmospheric ${ }^{14} \mathrm{CO}_{2}$ values of the given year that the growing season took place. At the sorghum site, the $\mathrm{Fm}^{14} \mathrm{C}$ value of the bulk biomass harvested at the ambient $\mathrm{CO}_{2}$ plot matched with the $\mathrm{Fm}^{14} \mathrm{C}$ value of the $\mathrm{CO}_{2}$ of the year of harvest (e.g., $\mathrm{Fm}^{14} \mathrm{C} \approx 1.097$, equivalent to the atmospheric ${ }^{14} \mathrm{CO}_{2}$ signature measured from clean air in 1999 - http://calib.qub.ac. uk/CALIBomb/ database and calibration software). This ${ }^{14} \mathrm{C}$ signature is higher than the present-day ambient $\mathrm{CO}_{2}$ due to nuclear weapon tests carried out during the 1950s and 1960s (Levin, 1997; Levin et al., 2013). The nuclear weapon tests doubled the ${ }^{14} \mathrm{C}$ content in the atmosphere, which created an isotopic chronometer (the ${ }^{14} \mathrm{C}$ bomb peak) during the last 60 years for all living organisms. At the durum wheat site, however, the ${ }^{14} \mathrm{C}$ signature of the biomass harvested at the ambient $\mathrm{CO}_{2}$ plot was slightly depleted $\left(\mathrm{Fm}^{14} \mathrm{C} \approx 1.017\right)$, as expected for $\mathrm{CO}_{2}$ above urban areas in Europe in the early 2010s. For comparison, the ${ }^{14} \mathrm{C}$ signature of atmosphericclean $\mathrm{CO}_{2}$ stations in Central Europe was $\mathrm{Fm}^{14} \mathrm{C}=1.040$ in 2012 (Levin, 1997; Levin et al., 2013).

\subsubsection{Below-ground C manipulation experiment}

The second experiment relies on the simultaneous response of phytC to different carbon amendment treatments of grasses grown under photosynthetic natural conditions (i.e., ambient $\mathrm{CO}_{2}$ air). Sorghum bicolor plants were grown outdoors in a ventilated area at the University of California, Irvine (UCI, USA), in six well-drained $40 \mathrm{~L}$ planters (A, $\mathrm{B}, \mathrm{C}, \mathrm{D}, \mathrm{E}$ and $\mathrm{F}$ ) filled with mineral substrates. Five of the planters were enriched with organic nutrients characterized by a broad range of ${ }^{14} \mathrm{C}$ signatures (from bomb spiked to fossil - Tables 1 and 2), while the last contained an inorganic nutrient devoid of $\mathrm{C}$ as a control (Planter F). Although much concerning the direct root absorption of natural carbon remains unknown, beneficial responses of root and plant growth have been reported in association with the addition of either inorganic carbon (Hibberd and Quick, 2002) and/or humic acids (Nardi et al., 2002). Consequently, we chose as substrate for Planter B, a natural carbonate-based sedimentary deposit mixed with organic carbon detritus of 
equal/even-age. For Planter E, fossil humic acids (extracted from leonardite) were chosen as the OC source.

Plants were fed as needed solely with $2 \mathrm{~L}$ of ultra-pure water (Planter A), or with a combination of ultra-pure water and their respective fertilizers and $\mathrm{SiO}_{2}$ providers (Planters BF) at a concentration of $1 \%(v / v)$ (Table 2). Additionally, the $\mathrm{CO}_{2}$ in the air surrounding the planters was isotopically monitored by collecting air in evacuated $6 \mathrm{~L}$ cylinders for the duration of the experiment with the purpose of characterizing the local atmospheric $\mathrm{CO}_{2}$ close to planters, and to serve as a reference for the ${ }^{14} \mathrm{C}$ signatures expected from plant tissue organs. Also, we isotopically measured commercial (sorghum) seeds to check if their ${ }^{14} \mathrm{C}$ signatures were recent. Finally, $\mathrm{CO}_{2}$ fluxes respired from the planter substrates were also sampled to evaluate their putative contribution to the phytC ${ }^{14} \mathrm{C}$ signature. After 3.5 months the Sorghum bicolor plants (stem and leaf) were harvested in preparation for phytolith extractions and isotopic analyses.

\subsection{Laboratory procedures}

\subsubsection{Plant treatment and phytolith extraction}

Stems and leaves samples (50-100 g each) were thoroughly rinsed with warm ultrapure water to remove air-dust, dried at $60^{\circ} \mathrm{C}$ and ground using an industrial mill (IKA ${ }^{\circledR} \mathrm{M} 20$ Universal Mill). About $10 \mathrm{mg}$ of each sample was kept for bulk tissue ${ }^{14} \mathrm{C}$ and $\delta^{13} \mathrm{C}$ analyses.

Four phytolith extraction protocols with increasing aggressiveness (via organic compound oxidation and silica dissolution) were used to treat the samples from the above-ground $\mathrm{C}$ manipulation experiment (Fig. 2). The protocols have been previously described in detail by Corbineau et al. (2013). They are based either on acid digestion and alkali or on multistep dry ashing and acid digestion. They are summarized below and in Fig. 2.

Protocols $1 a$ and $1 b$. Plant samples were subject to strong wet-digestion steps in order to oxidize the organic matter (e.g., $1 \mathrm{~N} \mathrm{HCl} 2 \mathrm{~h}^{-1}$, hot $\mathrm{H}_{2} \mathrm{SO}_{4} 24 \mathrm{~h}^{-1}$ plus $30 \% \mathrm{H}_{2} \mathrm{O}_{2}$ for 2-3 days, and $>65 \% \mathrm{HNO}_{3}$ plus $1 \mathrm{~g} \mathrm{KClO}_{3}$ for $24 \mathrm{~h}$ ). This was followed by $30 \mathrm{~min}$ of immersion in $\mathrm{KOH}$ solution at pH 11 (protocol 1a) or pH 13 (protocol 1b). The KOH immersions allowed final removal of any alkali-soluble forms of organic compounds remaining on phytolith surfaces.

Protocols $2 a$ and $2 b$. Plant samples were subjected to dryashing. Stepwise increases in temperature were used from 300 to $500^{\circ} \mathrm{C}$ and the samples were then kept at $500^{\circ} \mathrm{C}$ for $6 \mathrm{~h}$ (protocol 2a) or $12 \mathrm{~h}$ (protocol 2b). Samples were then digested in a $>65 \% \mathrm{HNO}_{3}$ and $70 \% \mathrm{HClO}_{4}$ mixture $(2: 1)$.

In order to assess local ${ }^{14} \mathrm{C}$ contamination during chemical extractions, four laboratories were involved in the extractions. They are UCI (USA), CEREGE (CNRS, AIx-Marseille University, France), the Soils and Sediments Analysis Lab (SSAL, the University of Wisconsin-Madison, USA), and the National Lacustrine Core Facility (LacCore, the Univer- sity of Minnesota, Twin Cities, USA). Aliquots of pre-baked $\left(900{ }^{\circ} \mathrm{C} 3 \mathrm{~h}^{-1}\right)$ silicon dioxide powder $\left(\mathrm{SiO}_{2}\right.$; mesh\# -325 , Sigma Aldrich, St. Louis, MO, USA) were chemically pretreated in parallel with the plant samples, and later analyzed as phytolith extract to provide independent blank data for each laboratory following the procedures described in Santos et al. (2010).

Due to the limited amount of plant biomass produced by the below-ground $\mathrm{C}$ manipulation experiment (Sect. 2.1.2), only two protocols were tested ( $1 \mathrm{a}$ and $2 \mathrm{~b}$ ) at only three of the laboratories (UCI, CEREGE, and LacCore), followed by blank sample materials as required.

\subsubsection{Soil extraction fractions}

Soils from the above-ground $\mathrm{C}$ manipulation experiment were physically cleaned of roots and stones. The bulk SOM fraction was isolated after carbonate removal in $1 \mathrm{~N} \mathrm{HCl}$ baths at $60^{\circ} \mathrm{C}$. The refractory (alkali-insoluble) fraction was further isolated via multiple baths in $1 \mathrm{M} \mathrm{NaOH}$ at $60^{\circ} \mathrm{C}$, followed by $1 \mathrm{~N} \mathrm{HCl}$ rinses (Santos and Ormsby, 2013). Upon chemical treatment, samples were adjusted to $\mathrm{pH}$ neutral and dried in a vacuum oven (Savant RT 100A refrigerated vapor vacuum pump system).

Amendments from the below-ground $\mathrm{C}$ experiment were not subject to any chemical pretreatment, except for the tests performed to small aliquots of greensand (GS, Table 1), allowing us to isolate the organic fraction from its bulk mixture.

\subsection{3 $\mathrm{CO}_{2}$ flux measurements}

In the frame of the below-ground $\mathrm{C}$ manipulation experiment, the rate of $\mathrm{CO}_{2}$ respired from Sorghum bicolor foliage (after sprouting), root systems and substrate was measured using closed dynamic soil $\mathrm{CO}_{2}$ flux chambers (Czimzik et al., 2006). Chamber headspace gasses were circulated through an infrared gas analyzer $(840,1400$, LI-COR, Lincoln, NE, USA), for 6 min at $0.5 \mathrm{~L}$ per minute, and the $\mathrm{CO}_{2}$ concentration was recorded every second. Once headspace $\mathrm{CO}_{2}$ concentrations reached twice that of ambient-air, the $\mathrm{CO}_{2}$ was collected in a molecular sieve trap for isotopic analysis, followed by ambient-air samples to serve as references.

\subsection{Analytical procedures}

\subsubsection{Phytolith concentrate purity analysis}

Small particulate organic contamination of phytolith concentrates may considerably bias isotopic and quantitative analyses of phytC. The purity of the phytolith concentrates was thus verified by Scanning Electron Microscopy with Energydispersive X-ray spectroscopy (SEM-EDS) (Corbineau et al., 2013). Extracted phytoliths, mounted directly on pre-cleaned aluminum stubs, were analyzed with a Schottky Thermal Field Emission FEI/Philips XL-30 SEM with back-scattering 
(a)

Sorghum Ambient $\mathrm{CO}_{2}$
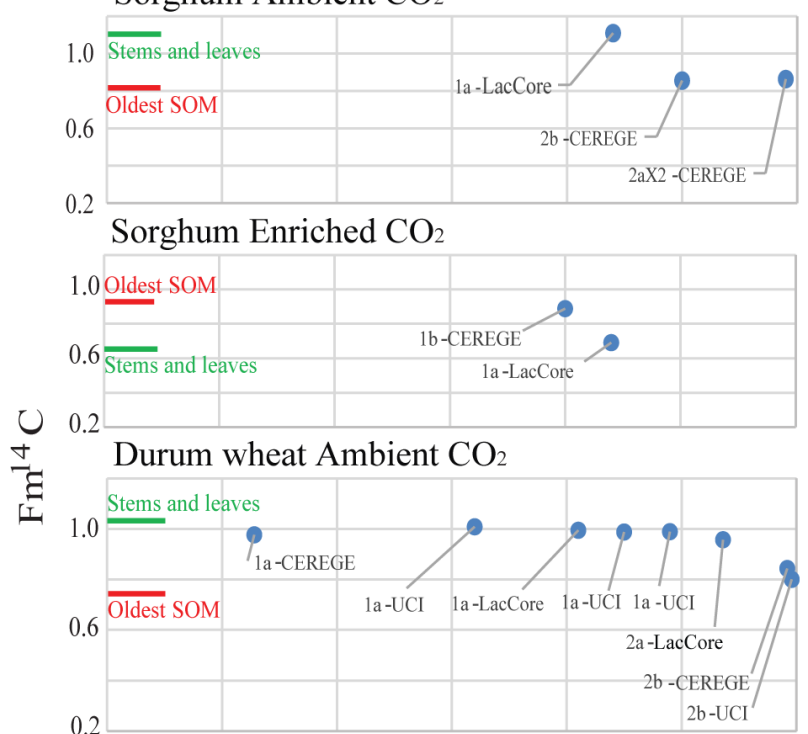

Durum wheat Enriched $\mathrm{CO}_{2}$

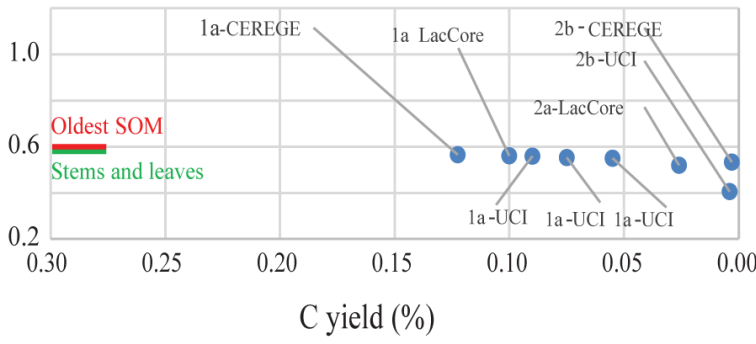

(b)
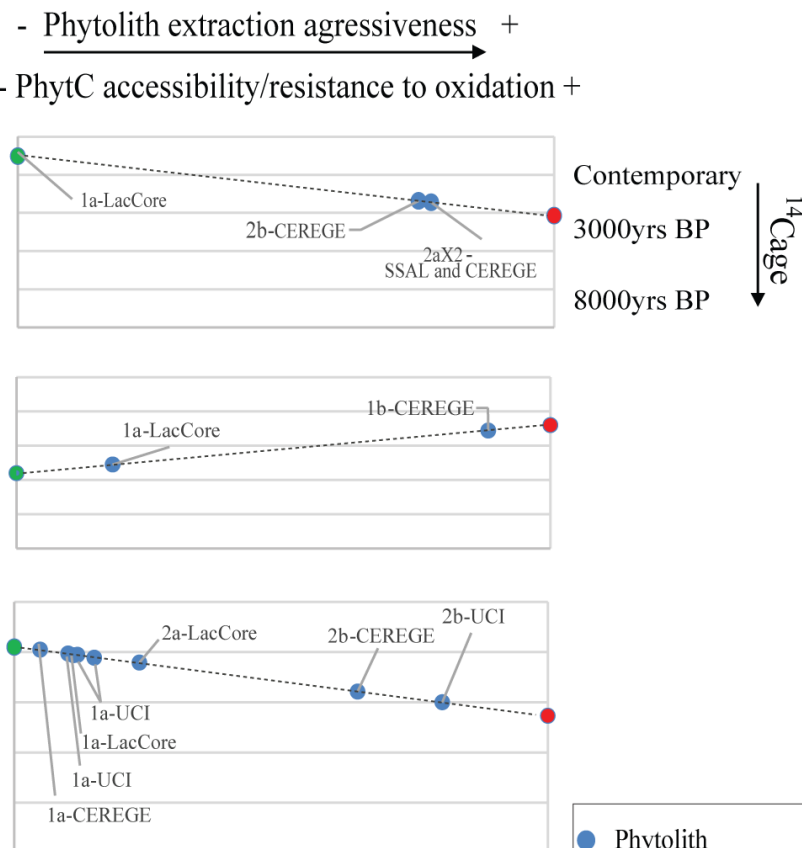

Phytolith

- Stems and leaves

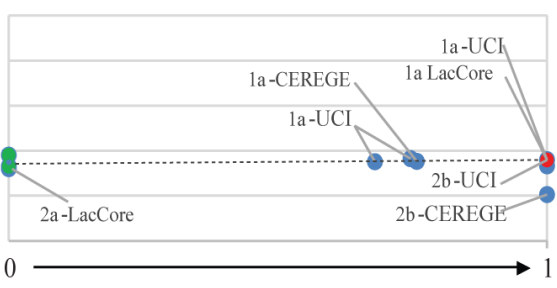

- Oldest extracted SOM

\begin{tabular}{|c|c|c|c|}
\hline \multicolumn{4}{|c|}{ Phytolith extraction protocol } \\
\hline & Dominant steps & Characteristic steps & Silica dissolution \\
\hline la & Acid/Alkaline & KOH solution@pH 11 & + \\
\hline $1 b$ & Acid/alkaline & KOH solution@pH 14 & ++ \\
\hline $2 a$ & Acid/Combustion & $6 \mathrm{H} 500^{\circ} \mathrm{C}$ combustion & - \\
\hline $2 b$ & Acid/Combustion & $12 \mathrm{H} 500^{\circ} \mathrm{C}$ combustion & - \\
\hline
\end{tabular}

Figure 2. Above-ground $\mathrm{C}$ manipulation procedure. (a) Averaged $\mathrm{Fm}^{14} \mathrm{C}$ values versus averaged phytC yields (or concentration in $\%$ of phytoliths). Constant solid lines correspond to the averaged $\mathrm{Fm}^{14} \mathrm{C}$ values obtained for stems and leaves (SL) of origin and the oldest extracted SOM fraction. (b) Oldest SOM-derived C contribution to phytC calculated using the mixing equation (Eq. 1) presented in the text expressing the ${ }^{14} \mathrm{C}$ signature of phytC as the result of mixing between the $\mathrm{C}$ derived from plant photosynthesis and the $\mathrm{C}$ derived from the oldest extracted SOM fraction. Phytolith samples are labeled according to the extraction protocol (1a, 1b, 2a, 2b described in caption and in the text) used and the laboratory of extraction (UCI, CEREGE, LacCore and SSAL).

electron detector. EDS semi-quantitative analyses of $\mathrm{C}$ and $\mathrm{Si}$ were obtained from 10 to $30 \mu \mathrm{m}$ locations on selected particles. Special attention was paid to organic-like particles showing tissue-like or non-phytolith morphologies. A total of $\sim 30$ analyses per sample were made. Samples with all $\mathrm{C}$ : Si peaks area ratios $<0.1$ were reported as devoid of organic particles. The equal/even accuracy and precision of the EDS analyses were evaluated by multiple measurements of a silicon carbide (SiC) standard (\#9441, Micro-Analyses Con- sultant Instrument Ltd, St Ives, UK): mean value of C : $\mathrm{Si}$ $\mathrm{M}=1.17$; standard deviation $\mathrm{SD}=0.02(n=21)$.

\subsubsection{Stable isotope analysis}

Stems/leaves, SOM fractions, nutrients/fertilizers and phytolith samples were analyzed for their total $\mathrm{C}$ content and stable $\mathrm{C}$ isotope ratio $\left(\delta^{13} \mathrm{C}\right)$ using a continuous flow stable isotope ratio mass spectrometer (Delta-Plus CFIRMS) inter- 
Table 1. Below-ground experiment. Details of substrate amendments, their carbon content, radiocarbon values (as $\mathrm{Fm}{ }^{14} \mathrm{C}$ and ${ }^{14} \mathrm{C}$ age) and $\mathrm{C}$ isotopic signatures.

\begin{tabular}{|c|c|c|c|c|c|c|c|c|}
\hline Name & Major contents & $\begin{array}{r}\mathrm{Fm}^{14} \mathrm{C} \\
\% \mathrm{C} \mathrm{(mass})^{\mathrm{a}}\end{array}$ & $\pm 1 \sigma$ & ${ }^{14} \mathrm{C}$ age & $\pm 1 \sigma$ & $\pm 1 \sigma$ & $\delta^{13} \mathrm{C}(\% \circ)$ & \\
\hline \multirow[t]{2}{*}{ Miracle Gro ${ }^{\circledR}(\mathrm{MG})$} & $\begin{array}{l}\text { Sphagnum Moss, Perlite, } \\
\text { Compost, } \mathrm{NH}_{4} \mathrm{NO}_{3} \text {, } \\
\left(\mathrm{NH}_{4}\right)_{3} \mathrm{PO}_{4}, \\
\mathrm{Ca}_{3}\left(\mathrm{PO}_{4}\right)_{2}, K_{2} \mathrm{SO}_{4}\end{array}$ & $49.5(n=2)$ & 1.0849 & 0.0028 & $-650^{\mathrm{b}}$ & 25 & -26.1 & 0.1 \\
\hline & & & 1.0123 & 0.0028 & $-95^{\mathrm{b}}$ & 25 & -25 & 0.1 \\
\hline Greensand (GS) & $\begin{array}{l}\text { Glauconite with organic and in- } \\
\text { organic detritus, } \mathrm{MnO}_{2}, \mathrm{SiO}_{2}\end{array}$ & $0.10^{\mathrm{c}}$ & $0.1591(n=2)$ & 0.0016 & 14765 & 78 & $\begin{array}{r}-24.3(\mathrm{OC} ; n=4) \\
-12.6(\text { bulk })\end{array}$ & 0.1 \\
\hline Ionic Grow (IG) & $\begin{array}{l}\mathrm{Ca}\left(\mathrm{NO}_{3}\right)_{2}, \mathrm{KNO}_{3}, \mathrm{H}_{3} \mathrm{PO}_{4}, \\
\mathrm{HNO}_{3}, \mathrm{~K}_{2} \mathrm{SO}_{4}\end{array}$ & 0.8 & $0.0374(n=2)$ & 0.0101 & 26550 & 2192 & -26.4 & 0.1 \\
\hline Earth juice (EJ) & $\begin{array}{l}\text { Kelp meal, } \quad \mathrm{MgSO}_{4} \text { borax, } \\
\mathrm{CoSO}_{4}, \\
\mathrm{FeSO}_{4}, \quad \mathrm{MnSO}_{4}, \quad \mathrm{Na}_{2} \mathrm{MoO}_{4}, \\
\mathrm{ZnSO}_{4}\end{array}$ & $15.44(n=2)$ & $0.4991(n=3)$ & 0.0013 & 5583 & 24 & $-24.1(n=2)$ & 0.2 \\
\hline Fossil Fuel (FF) & $\begin{array}{l}\text { Humic acids (from leonardite } \\
\text { or lignite coal) }\end{array}$ & $33.04(n=2)$ & 0.0055 & 0.0003 & 43340 & 1700 & $-26.2(n=2)$ & 0.2 \\
\hline Inorganic in-house fertilizer (IF) ${ }^{\mathrm{d}}$ & $\begin{array}{l}\mathrm{NaH}_{2} \mathrm{PO}_{4}, \mathrm{MgSO}_{4}, \mathrm{Ca}\left(\mathrm{NO}_{3}\right)_{2} \\
\mathrm{KNO}_{3}\end{array}$ & - & - & - & - & - & - & - \\
\hline Silica Blast $(\mathrm{SB})^{\mathrm{d}}$ & $\mathrm{Na}_{2} \mathrm{SiO}_{3}, \mathrm{~K}_{2} \mathrm{SiO}_{3}$ & - & - & - & - & - & - & 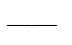 \\
\hline
\end{tabular}

Table 2. Below-ground experiment. Planters' major features: substrates and amendments, living plant appearance, biomass by dwt and phytolith yields. All nutrients and fertilizers were administered in aqueous solutions, except for MG. In bold: main amendment.

\begin{tabular}{lllllll}
\hline & A & B & C & D & E & F \\
\hline Substrate & MG & GS & Baked Sand & Baked Sand & Baked Sand & Baked Sand $^{\text {Band }}$ \\
Amendments & In MG & In GS, IG & IG $^{\text {a }}$ & EJ, IF & FF, IF & IF $^{\text {b }}$ \\
Silica Provider & In MG & In GS & SB & SB & SB & SB \\
Appearance & Dark green & Dark green & Dark green & Green & Yellowish green & Green \\
Biomass (g) & 98.57 & 79.09 & 89.24 & 86.67 & 54.78 & 53.37 \\
Phytolith yield & 0.12 & 0.78 & 0.83 & 0.83 & 1.77 & 1.35 \\
\hline
\end{tabular}

${ }^{\mathrm{a}}$ IG has a very low $\% \mathrm{C}$. Therefore, its $\mathrm{C}$ contribution to planters $\mathrm{B}$ and $\mathrm{C}$ after dilution into solution (e.g., $\sim 0.02 \mathrm{~g}$ of $\mathrm{C}$ per feeding) was found to be very small, a conclusion supported by isotopic analyses (Table S3); ${ }^{\text {b }}$ IF (which does not contain measurable amounts of C) was added to those planters to supply micronutrients to support plant growth; ${ }^{\mathrm{c}}$ as $\%$ of dry leaf and stem biomass combined.

faced with a Fisons NA-1500NC (for solid materials) and a Gasbench II (for $\mathrm{CO}_{2}$ input).

About $10 \mathrm{mg}$ of phytoliths and $25 \mathrm{mg}$ of soil were weighed out into pre-baked $\left(100^{\circ} \mathrm{C}\right.$ per $\left.2 \mathrm{~h}\right)$ tin capsules $(5 \times 9 \mathrm{~mm}$ capsules from Costech Analytical Technologies Inc., Valencia, CA, USA) using a pre-calibrated microbalance (Sartorius $A G$, Göttingen, Germany). For accurate integration and calibration of carbon peaks of phytolith samples $(\sim 0.1 \% \mathrm{C})$, measurements were obtained by decreasing the helium carrier flow rate, and by measuring several size-matched aliquots of standards from the National Institute of Standards Technology. Aliquots of $\mathrm{SiO}_{2}$ blanks and fossil phytoliths (MSG70) used as an internal standard at CEREGE (Alexan- dre et al., 2015; Crespin et al., 2008) were included for background corrections and accuracy (Santos et al., 2010), respectively. For the bulk tissue samples, aliquots of $\mathrm{CO}_{2}$ gas were recovered after combustion, and sent to CFIRMS, which has a typical precision of $0.1 \%$. Stable isotope results are reported as $\delta$ values in \%o relative to the Vienna Pee Dee Belemnite (vPDB).

\subsubsection{Radiocarbon analysis}

Stems/leaves, SOM fractions, nutrients/fertilizers, $\mathrm{CO}_{2}$ and phytolith samples were processed for ${ }^{14} \mathrm{C}$ accelerator mass spectrometry (AMS) analyses. About $2 \mathrm{mg}$ of plant tis- 
sue, $20-100 \mathrm{mg}$ of SOM and $15-300 \mathrm{mg}$ of phytoliths were loaded for tube-sealed combustion (Santos et al., 2004). To avoid $\mathrm{CO}_{2}$ adsorption on phytolith surfaces, the loaded samples were kept and transferred warm $\left(\right.$ at $\left.160{ }^{\circ} \mathrm{C}\right)$ to the evacuated line for sealing (Santos et al., 2010). Liquid solutions were freeze-dried directly into tubes prior to combustion. Atmospheric $\mathrm{CO}_{2}$ was extracted from $6 \mathrm{~L}$ collection flasks of whole air, by attaching the flasks to an evacuated line. A similar procedure was used to recover the $\mathrm{CO}_{2}$ collected in molecular sieve traps (from flux chambers). Once the $\mathrm{CO}_{2}$ was cryogenically separated from other gases, it was then transferred to a Pyrex tube at a flame-off port and sealed (Santos et al., 2010). Samples of $\mathrm{CO}_{2}$ from tube-sealed combustions, flasks and traps were cryogenically isolated, and reduced to graphite (Santos et al., 2007; Xu et al., 2007), or transferred to Gasbench II CFIRMS for isotopic analysis.

The ${ }^{14} \mathrm{C}$ measurements were performed at the KeckCCAMS Facility (UCI). Precision and accuracy in measurements on $>0.7 \mathrm{mg}$ of near-modern carbon samples are typically $0.2-0.3 \%$ (Beverly et al., 2010), and $1 \%$ on samples in the $0.01 \mathrm{mg} \mathrm{C}$ range (Santos et al., 2007). The instrument provides the isotopic ratio ${ }^{13} \mathrm{C} /{ }^{12} \mathrm{C}$, allowing for fractionation effects (either spectrometer induced or arising from biochemical processes) to be corrected for all targets measured.

Blanks from $\mathrm{SiO}_{2}$ aliquots were also measured to provide background corrections. All labs and extraction protocols showed similar procedural blanks $(\sim 0.003 \mathrm{mg}$ of modern $\mathrm{C}$ and $\sim 0.002 \mathrm{mg}$ of ${ }^{14} \mathrm{C}$ free ${ }^{1}$. Those values were subtracted from the ${ }^{14} \mathrm{C}$ data, including the results obtained from the MSG70 reference material, for accuracy. Details on such background subtractions can be found elsewhere (Santos et al., 2010). Radiocarbon results were expressed as $\mathrm{Fm}^{14} \mathrm{C}$ and when appropriate were discussed as ages.

\subsubsection{Thermal analysis}

We performed thermal analysis of phytoliths on a modified Thermal-Optical Carbon Aerosol Analyzer (RT 3080, Sunset Laboratory Inc.) (Bae et al., 2004). Phytolith concentrates of 7-10 mg were loaded onto a customized spoon (Jelight Company, Inc. USA), placed into the instrument and kept at $50^{\circ} \mathrm{C}$ for $\sim 10 \mathrm{~min}$ for surface cleansing. The stepwise temperature ramp started at $50^{\circ} \mathrm{C}$ and ended at $850^{\circ} \mathrm{C} 50$ min later. Pure oxygen $\left(65 \mathrm{~mL} \mathrm{~min}^{-1}\right)$ was used to avoid refractory carbon (char) formation. The $\mathrm{CO}_{2}$ evolved was injected into a manganese dioxide oven at $870^{\circ} \mathrm{C}$, and later quantified by a non-

\footnotetext{
${ }^{1}$ The term ${ }^{14} \mathrm{C}$ free is used in association with materials from which the original ${ }^{14} \mathrm{C}$ radioisotope content has been reduced to zero or close to zero. However, those materials obviously continue to maintain their stable amounts of ${ }^{12} \mathrm{C}$ and ${ }^{13} \mathrm{C}$. Consequently, the addition of ${ }^{14} \mathrm{C}$ free (or organic carbon from subfossil ${ }^{14} \mathrm{C}$ signatures) to pools of $\mathrm{C}$ containing present-day atmospheric $\mathrm{CO}_{2}$ signals will lower the overall ${ }^{14} \mathrm{C}$ signature of the pool. For each $1 \%$ fossil $\mathrm{C}$ present, an offset of 80 years is expected (Santos et al., 2016, and reference therein).
}

dispersive infrared detector. Typical multi-point calibration curves, when analyzing known quantities of $\mathrm{C}$ ranging from $2-120 \mu \mathrm{g}$, yielded correlation coefficients greater than 0.998 .

Two phytolith samples were analyzed. Durum wheat leaf phytoliths extracted using protocol 1a, and MSG70, made of highly weathered fossil phytoliths (Alexandre et al., 2015; Crespin et al., 2008).

\section{Results and discussions}

\subsection{Isotopic results from above-ground $\mathrm{C}$ manipulation experiments}

A total of 21 individual phytolith concentrates were produced for the above-ground experiments by all laboratories involved in this project. Those samples are tabulated in the Supplement (Tables S1 and S2), followed by details on the sample processing (protocols, laboratory and measurement identifiers). Note that when sufficient plant material was available (which was the case for the durum wheat samples) some labs could replicate the extraction (i.e., processing the same pool of biomass following the same protocol).

From those 21 phytolith concentrates, $51{ }^{14} \mathrm{C}$ results were produced to determine the phytC ${ }^{14} \mathrm{C}$ signatures (number of targets includes duplicates and/or replicates, as specified in Tables S1 and S2). Two phytC ${ }^{14} \mathrm{C}$ targets from MSG70, a fossil phytolith internal standard at CEREGE, were also produced to evaluate measurement reproducibility. Overall, the precision and accuracy of the phytC ${ }^{14} \mathrm{C}$ data were better than $0.3 \%$, based on duplicates and triplicates of graphite samples $>0.5 \mathrm{mg} \mathrm{C}$. For the smaller sized samples, $1 \%$ or better were recorded in most cases, even after background corrections based on measurements of multiple $\mathrm{SiO}_{2}$ aliquots were propagated into individual uncertainties (Tables S1 and S2). We have not identified significant differences in interlaboratory analyses when using the same protocol on subsamples of the same biomass sample, and/or when evaluating procedural blank materials (added to every batch analyzed details in Sect. 2.3.3). To help with determining the phytC carbon sources, other ${ }^{14} \mathrm{C}$ results shown in Tables S1 and S2 are from the stems/leaves and SOM fractions (e.g., the carbon pools associated with the labile-accessible and recalcitrant (alkali-insoluble)).

PhytC concentrations were consistent for a given extraction method but showed a clear decreasing trend with increasing protocol aggressiveness. The phytC yields (phytC \% relative to the d.wt of phytoliths) averages ranged from 0.24 $0.06 \%$ for the less aggressive protocols $1 \mathrm{a}$ and $1 \mathrm{~b}$ and from 0.05 and $0.002 \%$ for the more aggressive protocols $2 \mathrm{a}$ and $2 \mathrm{~b}$ (Fig. 2a, and Tables S1, S2).

Phytoliths extracted from either sorghum or durum wheat using protocol 1a produced phytC ${ }^{14} \mathrm{C}$ signatures closest to the values of the stems and leaves of origin regardless of air $\mathrm{CO}_{2}$ concentration (ambient vs. enriched $\mathrm{CO}_{2}$ ) and grass 
species (Fig. 2b). However, phytC ${ }^{14} \mathrm{C}$ offsets were still evident when compared to the expected values given the year of harvest or artificial tagging (Table S1). For sorghum, absolute offsets varied from 85 (UCIAMS123579 and 123580) to 610 years (UCIAMS123577 and 123578) when using protocol 1a. The maximum offset increased when using protocols $1 \mathrm{~b}$ (2633 years; UCIAMS95338), 2a (1920 years; UCIAMS130339), and $2 \mathrm{~b}\left(1990{ }^{14} \mathrm{C}\right.$ years; UCIAMS95335 to 95337). Durum wheat ambient phytC ${ }^{14} \mathrm{C}$ absolute offsets varied from 105 (UCIAMS123572) to 1925 years (UCIAMS125986), while phytC offsets from enriched plots varied from 310 (UCIAMS123570 and 123571) to 2885 years (UCIAMS125983).

The hypothesis that there is a contribution of SOM-derived $\mathrm{C}$ to phytC was tested estimating phytC as a mixture of (i) $\mathrm{C}$ derived from plant photosynthesis and (ii) $\mathrm{C}$ derived from the oldest SOM fraction measured. The mixing equation is

Oldest SOM-derived $\mathrm{C}$ contribution $=$

$\left(\mathrm{Fm}^{14} \mathrm{C}_{\mathrm{phytC}}-\mathrm{Fm}^{14} \mathrm{C}_{\mathrm{SL}}\right) /\left(\mathrm{Fm}^{14} \mathrm{C}_{\mathrm{SOM}}-\mathrm{Fm}^{14} \mathrm{C}_{\mathrm{SL}}\right)$

where the ${ }^{14} \mathrm{C}$ signatures of the oldest SOM, stems and leaves (SL) and phytC are expressed as $\mathrm{Fm}^{14} \mathrm{C}_{\mathrm{SOM}}, \mathrm{Fm}^{14} \mathrm{C}_{\mathrm{SL}}$ and $\mathrm{Fm}^{14} \mathrm{C}_{\text {phytC. }} \mathrm{Fm}^{14} \mathrm{C}_{\text {phytC }}$ was expressed relative to $\mathrm{Fm}^{14} \mathrm{C}_{\text {SOM }}$ (assigned a contribution value of 1 ) and $\mathrm{Fm}^{14} \mathrm{C}_{\mathrm{SL}}$ (assigned a contribution value of 0 ). The average $\mathrm{Fm}^{14} \mathrm{C}$ value of the oldest SOM-C fractions measured in each experiment (i.e., the $\mathrm{Fm}^{14} \mathrm{C}$ average value of the SOM $45-60 \mathrm{~cm}$ fraction for S. bicolor plots - Table S1 in Supplement, and the refractory $0-15 \mathrm{~cm}$ fraction for T. durum plots - Table S2) were used for $\mathrm{Fm}^{14} \mathrm{C}_{\mathrm{SOM}}$.

The mixing curves associated with the SOM-derived $\mathrm{C}$ to phytC hypothesis are presented in Fig. $2 \mathrm{~b}$. The $\mathrm{Fm}^{14} \mathrm{C}$ values of two phytC samples from the Sorghum Ambient $\mathrm{CO}_{2}$ experiment obtained using protocol 1a (UCIAMS123579 and 123580) and one phytC sample from the Durum Wheat Enriched $\mathrm{CO}_{2}$ experiment obtained using protocol $1 \mathrm{~b}$ (UCIAMS130339) were higher than $\mathrm{Fm}^{14} \mathrm{C}$ values of the stems and leaves of origin, indicating that the soil pool still has remnants of ${ }^{14} \mathrm{C}$-labeled OC from the 1950 s thermonuclear tests (Levin, 1997; Levin et al., 2013). In this case the SOMderived $\mathrm{C}$ was assigned a contribution value of 0 , and the stems and leaves a contribution value of 1 in Fig. 2b. Conversely, some of the phytC $\mathrm{Fm}^{14} \mathrm{C}$ values from the $\mathrm{Du}$ rum Wheat Enriched $\mathrm{CO}_{2}$ experiment, obtained using protocols 1a, 2a and 2b (UCIAMS123566, 123567, 125985, 130334 and 130335), were lower $\left({ }^{14} \mathrm{C}\right.$ age older) than the $\mathrm{Fm}^{14} \mathrm{C}$ value of the oldest $\mathrm{SOM}$ fraction or 1 in Fig. $2 \mathrm{~b}$. This pattern suggests that the so-called oldest SOM fraction, which is a mixture of old and young SOM (Schrumpf et al., 2013) may still be "younger" than present-day in terms of its ${ }^{14} \mathrm{C}$ signatures, if the soil $\mathrm{C}$ pool is still bearing some bomb-produced ${ }^{14} \mathrm{C} \mathrm{OC}$, or much older if aromatic complexes are dominant (Telles et al., 2003; Torn et al., 2009). For the sorghum experiment this trend was particularly ob- vious, as the ambient $\mathrm{CO}_{2}$ and the upper soil layers were clearly imprinted with bomb ${ }^{14} \mathrm{C}$ (Levin, 1997). Therefore, Fig. $2 \mathrm{~b}$ clearly showed that the phytC $\mathrm{Fm}^{14} \mathrm{C}$ values unambiguously trend toward the $\mathrm{Fm}^{14} \mathrm{C}$ value (or ${ }^{14} \mathrm{C}$ age) of the oldest SOM fraction. Overall, the crucial point to be noticed is that the phytC ${ }^{14} \mathrm{C}$ offsets shifted linearly towards negative values if the oldest SOM fraction was older than the biomass of origin (Sorghum Ambient and Durum Wheat Ambient, Fig. 2a), and towards positive values when the oldest SOM fraction was younger (Sorghum Enriched, Fig. 2a). Thus, phytC ${ }^{14} \mathrm{C}$ differences were clearly linked to the oldest $\mathrm{SOM}{ }^{14} \mathrm{C}$ ages. Moreover, the agreement in phytC ${ }^{14} \mathrm{C}$ values obtained from stems and leaves indicated that the offsets were not linked to plant anatomy.

Regarding $\delta^{13} \mathrm{C}$ values, the phytC offsets relative to the tissue of origin did not systematically trend towards SOM $\delta^{13} \mathrm{C}$ values, except for the Sorghum Ambient phytC undergoing the $2 \mathrm{~b}$ protocol $(-21.6 \pm 0.1 \% \circ(n=2)$ as indicated in Fig. 3; UCIAMS95335 and 95336). As described earlier, this protocol tends to isolate the most recalcitrant phytC fraction. The difference between phytC $\delta^{13} \mathrm{C}$ values of durum wheat and sorghum was higher $(\sim 15.7 \%$ o $)$ than the difference between $\delta^{13} \mathrm{C}$ values of the stems and leaves of origin (e.g., $\sim 5.6$ vs. $\sim 7.2 \%$ for wheat and sorghum, respectively), as previously reported for grasses with $\mathrm{C}_{3}$ and $\mathrm{C}_{4}$ photosynthetic pathways (Webb and Longstaffe, 2000, 2010). Without further discrimination of the molecular composition of SOMderived $\mathrm{C}$ absorbed by the plant roots, in-depth discussion of the $\delta^{13} \mathrm{C}$ differences between phytC and plant biomass is difficult. Nevertheless, the observed differences between phytC and stems and leaves $\delta^{13} \mathrm{C}$ values were consistent with previous calibration studies, and were explained by preferential occlusions of plant molecular ${ }^{13} \mathrm{C}$-depleted compounds in phytoliths (Webb and Longstaffe, 2010).

\subsection{Isotopic results from below-ground $\mathrm{C}$ manipulation experiments}

A total of 12 individual phytolith concentrates and phytC ${ }^{14} \mathrm{C}$ targets were produced for the below-ground experiments, two of those from the same biomass samples (from Planters A and C), but subjected to different degrees of oxidation (e.g., protocol $2 \mathrm{~b}$ ). Other ${ }^{14} \mathrm{C}$ results shown are from the stems/leaves, nutrients/fertilizers, and $\mathrm{CO}_{2}$ extracted from $6 \mathrm{~L}$ flasks and flux chambers (Fig. 4). The complete set of isotopic results and sample processing details are tabulated in the Supplement (Tables S3).

Phytoliths produced phytC yields ranged from 0.08 to $0.1 \% \mathrm{~d}$ wt when using the less aggressive protocol 1a and from $0.01-0.04 \% \mathrm{~d}$ wt when using the more aggressive protocol $2 b$ (Table S3).

Significant offsets of the phytC ${ }^{14} \mathrm{C}$ values relative to the stem and leaf $\mathrm{Fm}^{14} \mathrm{C}$ values were again found in association with the carbon sources in the soils (e.g., substrates/amendments). The highest phytC ${ }^{14} \mathrm{C}$ offset of 3610 
(a)

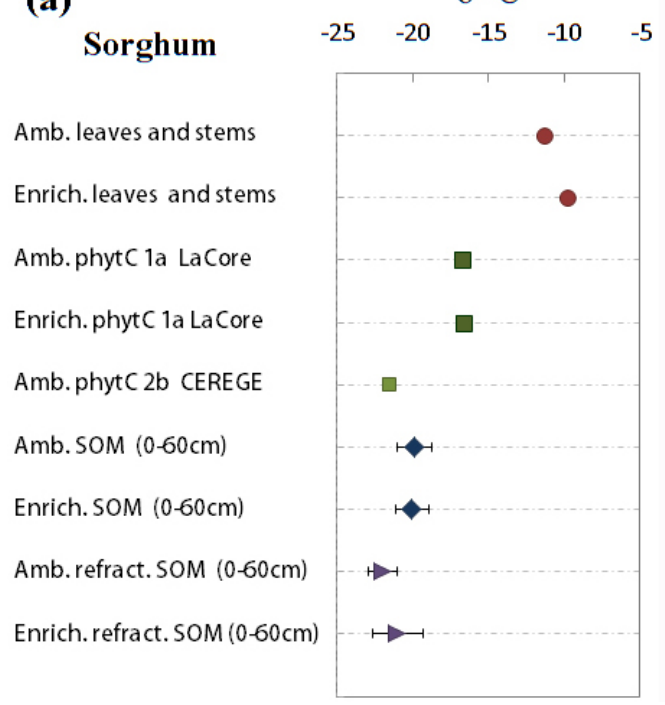

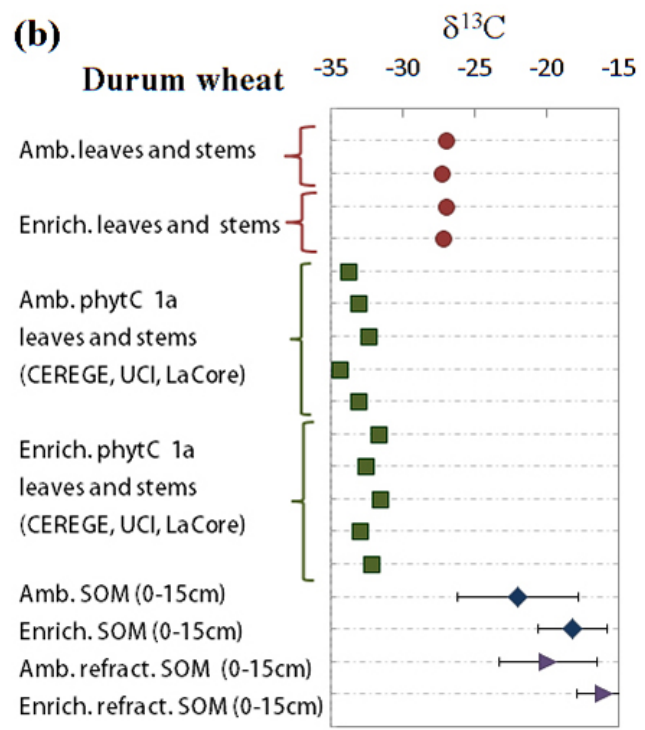

Figure 3. Above-ground $\mathrm{C}$ manipulation experiment. $\delta^{13} \mathrm{C}$ values of stems and leaves, phytC, and soil $\mathrm{SOM}$ fractions obtained for (a) sorghum and (b) durum wheat experiments. To facilitate comparisons between groups, samples from ambient and enriched $\mathrm{CO}_{2}$ plots are plotted next to each other. Values are reported as per mil (\%o) related to PDB. Results of the bulk and refractory SOM fractions were averaged; consequently results and uncertainties indicate multiple data points. Individual results are shown in Tables S1 and S2.

years (UCIAMS104366) was obtained from the phytC ${ }^{14} \mathrm{C}$ from Planter $\mathrm{B}$ when using protocol $2 \mathrm{~b}$, showing again that the increased age discrepancies were due to protocol aggressiveness (e.g., from 1a to $2 b$ ). The effect is also observed in the phytoliths associated with Planter $\mathrm{C}$, which received very low amounts of below-ground organic carbon relative to all other treatments (Tables 1 and 2). Specifically, the Planter $\mathrm{C}$ phytC ${ }^{14} \mathrm{C}$ offsets increased from 160 (UCIAMS130346; protocol 1a) to 1150 (UCIAMS104362; protocol 2b), and to 1760 years (UCIAMS104900; protocol 2b).

Even when we processed biomass samples from all Planters following the same protocol (such as the less aggressive 1a protocol), ${ }^{14} \mathrm{C}$ age discrepancies between phytC and the plant of origin were highly evident, and correlated to the ${ }^{14} \mathrm{C}$ signatures of amendments (UCIAMS130344 to 130348). PhytC ${ }^{14} \mathrm{C}$ offsets were greater for amendments containing sufficient amounts of $\mathrm{C}$ of extreme ${ }^{14} \mathrm{C}$-signatures (e.g., positive 320 years to Planter A, and negative 680 years to Planter E in Table S3). Note that the Planter A substrate was composed of rich bulk-complex OC imprinted with ${ }^{14} \mathrm{C}$ bomb values (or $\mathrm{Fm}^{14} \mathrm{C}$ signatures higher than present-day values), while the Planter $\mathrm{E}$ substrate received a solution of fossil $\mathrm{OC}\left(\mathrm{Fm}^{14} \mathrm{C}=0\right.$; close to $\sim 43 \mathrm{kyr} \mathrm{BP} ; n=3$ ) (Tables 1 and 2). As in the above $\mathrm{C}$ manipulation experiment, in Fig. 4 we assigned values of 0 and 1 to the $F m^{14} \mathrm{C}$ associated with stems and leaves of origin and amendments, respectively (Table S3), and used the same mixing equation (Eq. 1).

The bulk stems and leaves produced $\mathrm{Fm}^{14} \mathrm{C}$ signatures that were very similar to the local ambient air ${ }^{14} \mathrm{CO}_{2}$ values collected in the $6 \mathrm{~L}$ cylinders during the growing season, exclud- ing any possibility that the phytC ${ }^{14} \mathrm{C}$ depletions are a product of urban fossil atmospheric $\mathrm{CO}_{2}$ fixation. The small discrepancies between the stem and leaf ${ }^{14} \mathrm{C}$ values (e.g., from 25 to 65 years) (Table S3) are attributed to heterogeneities in $\mathrm{C}$ distribution within plant cells during $\mathrm{C}$ fixation (Pausch and Kuzyakov, 2011; Wichern et al., 2011). The commercial seeds of sorghum were also measured by ${ }^{14}$ C-AMS (Fig. 4) to verify their recent radiocarbon activity (UCIAMS83120 and 83121; Table S3). As expected, once early-fixed photosynthetic $\mathrm{CO}_{2}$ became dominant, remobilized ${ }^{14} \mathrm{C}$ from seeds made little contribution to mature biomass tissue.

Although $\mathrm{Fm}^{14} \mathrm{C}$ values of substrate $\mathrm{CO}_{2}$ fluxes were depleted towards amendment ${ }^{14} \mathrm{C}$ bulk signatures (UCIAMS83842 to 83845, Table S3), soil $\mathrm{CO}_{2}$ plant tissue refixation via photosynthesis (and its influence on phytC) was found to be negligible, and cannot be invoked to explain the anomalous phytC ${ }^{14} \mathrm{C}$ results. $\mathrm{CO}_{2}$ fluxes from the planters' substrates upon sprouting varied from 0.34 to $1.72 \mathrm{ppm} \mathrm{s}^{-1}$ $\left(\approx 10^{-5} \mathrm{~g} \mathrm{~m}^{-2} \mathrm{yr}^{-1}\right)$ (Table S3), indicating very little microbial activity. For comparison, global soil $\mathrm{CO}_{2}$ fluxes vary from 60 to $1000 \mathrm{~g} \mathrm{~m}^{-2} \mathrm{yr}^{-1}$ (Raich and Sclesinger, 1992).

$\delta^{13} \mathrm{C}$ offsets between phytC and stems and leaves were $\sim 6.5 \%$ on average, including the phytC from Planter $\mathrm{B}$ (which contain a mixed $\mathrm{C}$ pool of $\mathrm{OM}$ detritus of plant origin and carbonate deposits - Table 1), showing that the inorganic fraction of the soil $\mathrm{C}$ was not a significant source of phytC (Fig. 5). Also in Fig. 5, we show the stable isotopic signatures of the $\mathrm{CO}_{2}$ fluxes (UCIAMS83842 to 83845; Table S3) collected using closed dynamic soil $\mathrm{CO}_{2}$ flux chambers $(\mathrm{Cz}-$ imzik et al., 2006). The results fell mostly between the air 


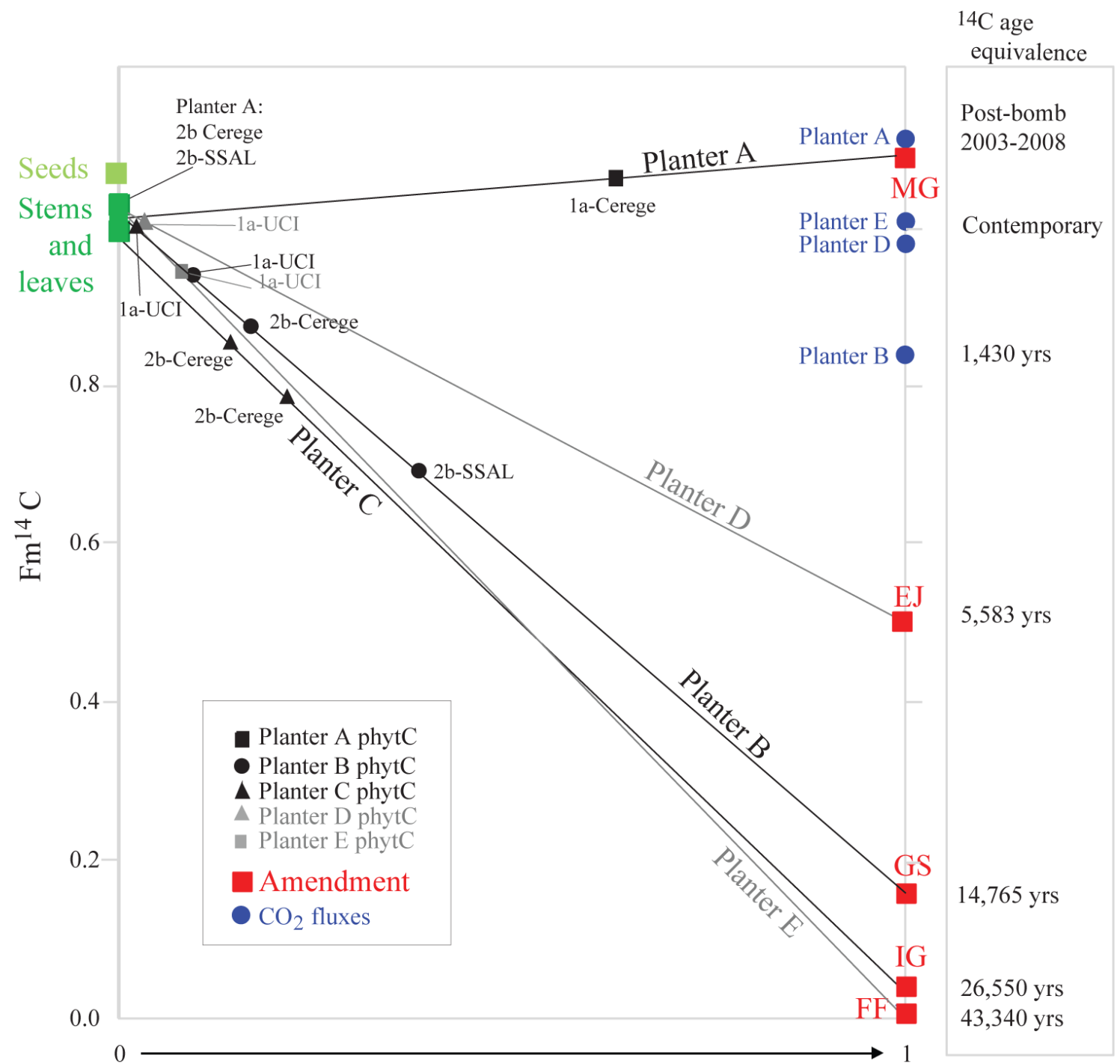

Oldest amendment derived-C contribution

Figure 4. Below-ground $\mathrm{C}$ manipulation procedure: oldest amendment-derived $\mathrm{C}$ contribution to phytC calculated using the mixing equation (Eq. 1) presented in the text expressing the ${ }^{14} \mathrm{C}$ signature of phytC as the result of mixing between $\mathrm{C}$ derived from plant photosynthesis (seeds, stems and leaves represented by the green squares) and C derived from the oldest amendment (MG, EJ, GS, IG, FF defined in Table 1 and represented by the red squares). Phytolith samples are labeled according to the phytolith extraction protocol used (1a and $2 \mathrm{~b}$ ) and the laboratory of extraction (UCI, CEREGE and SSAL). Selected age benchmarks from substrate amendments and soil $\mathrm{CO}_{2}$ fluxes are shown for reference on the right axis.

and bulk plant tissue averages, as expected for $\mathrm{CO}_{2}$ produced from above- and below-ground biomasses, supporting our previous observations of negligible effects of soil $\mathrm{CO}_{2}$ respired to phytC.

This data set clearly shows that amendment-derived C, adsorbed through root plants, altered the phytC ${ }^{14} \mathrm{C}$ signatures.

\subsection{Thermal stability of phytC}

Chemical compositional insights on carbonaceous materials can be obtained via oxidation reactivity to thermal treat- ments; such treatments have been frequently used on organic compounds from soils and sediments (Plante et al. 2011, 2013; Rosenheim et al., 2013). For instance, single-bonded carbon structures usually show a lower thermal stability than those dominated by double bonds, such as conjugated and aromatic structures (Harvey et al., 2012). Here, we make use of the same chemical-thermal stability concept to evaluate the heterogeneity of phytC in reacting to heat treatments.

Thermograms obtained from phytoliths of the durum wheat leaves and fossil phytoliths (MSG70) indicated a continuum of phytC $\mathrm{CO}_{2}$ with different degrees of resistance 


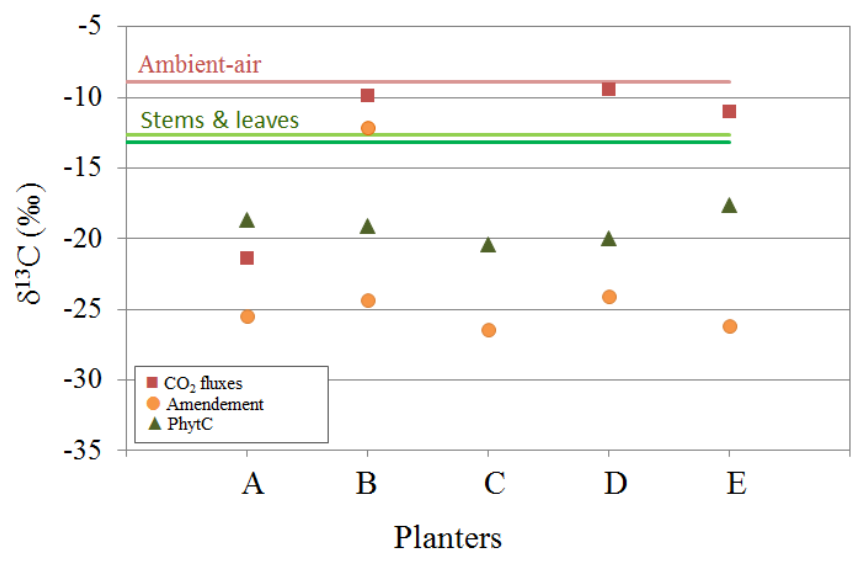

Figure 5. Below-ground $\mathrm{C}$ manipulation experiment. $\delta^{13} \mathrm{C}$ values of the respired $\mathrm{CO}_{2}$, stems and leaves, amendments and phytC for the five planters enriched in organic carbon nutrients (A-E). Values are reported as per mil (\%o) related to PDB, and individual symbols represent single results as reported in Table S3. For Planter B we report two values, its OC fraction $(-24.3 \%$ o) and its bulk fraction $(-12.1 \%$ - a mixture of OC and inorganic carbon) (Table 1). Constant solid lines correspond to the average $\delta^{13} \mathrm{C}$ values of ambientair $\mathrm{CO}_{2}$ and bulk plant tissues.

or accessibility (Fig. 6). Although the overall production of $\mathrm{CO}_{2}$ was lower for MSG70, the continuum temperaturedependency pattern of phytC was preserved. For example, at $250^{\circ} \mathrm{C}$ both phytolith extracts produced $\mathrm{CO}_{2}$, however the leaf phytoliths show lesser amounts of $\mathrm{CO}_{2}$ evolved than soil phytoliths. At $500^{\circ} \mathrm{C}$ half of the phytC $\mathrm{CO}_{2}$ in both samples has been evolved, and at $800^{\circ} \mathrm{C}$ all of the phytC has been completely removed.

Phytoliths typically melt at $\sim 573{ }^{\circ} \mathrm{C}$ (Deer et al., 1992), but embedded metals (e.g., $\mathrm{Al}, \mathrm{Fe}$ ) within their structures could lead to a decrease in temperature stability (Wu et al., 2014). Nevertheless, phytC that required much higher temperatures to fully oxidize (e.g., beyond of the phytolith melting point of $573^{\circ} \mathrm{C}$ ) would be placed at the upper end of the carbon recalcitrance continuum. (Cheng et al., 2013; Harvey et al., 2012; Plante et al., 2005, 2011, 2013). Furthermore, even if char occurred during combustion leading to some elemental carbon formation, it does not explain the $\mathrm{Fm}^{14} \mathrm{C}$ phytC discrepancies obtained here (Figs. 2 and 4) or elsewhere (Santos et al., 2010, 2012a, b; Sullivan and Parr, 2013; Yin et al., 2014).

Santos et al. (2012a) and Yin et al. (2014) also heated phytolith aliquots from a single extract, and observed shifts in ${ }^{14} \mathrm{C}$ ages towards older values. This effect is similar to that observed in total carbon or SOM distributions in soils and sediments when subject to thermal decomposability (Plante et al., 2011, 2013). Thus, phytolith extractions that employ heat treatments would better isolate the oldest soil C fraction within phytoliths, as previously found (in Sects. 3.1. and 3.2). Basically, if the $\mathrm{C}$ pool in phytoliths is supposedly ho-
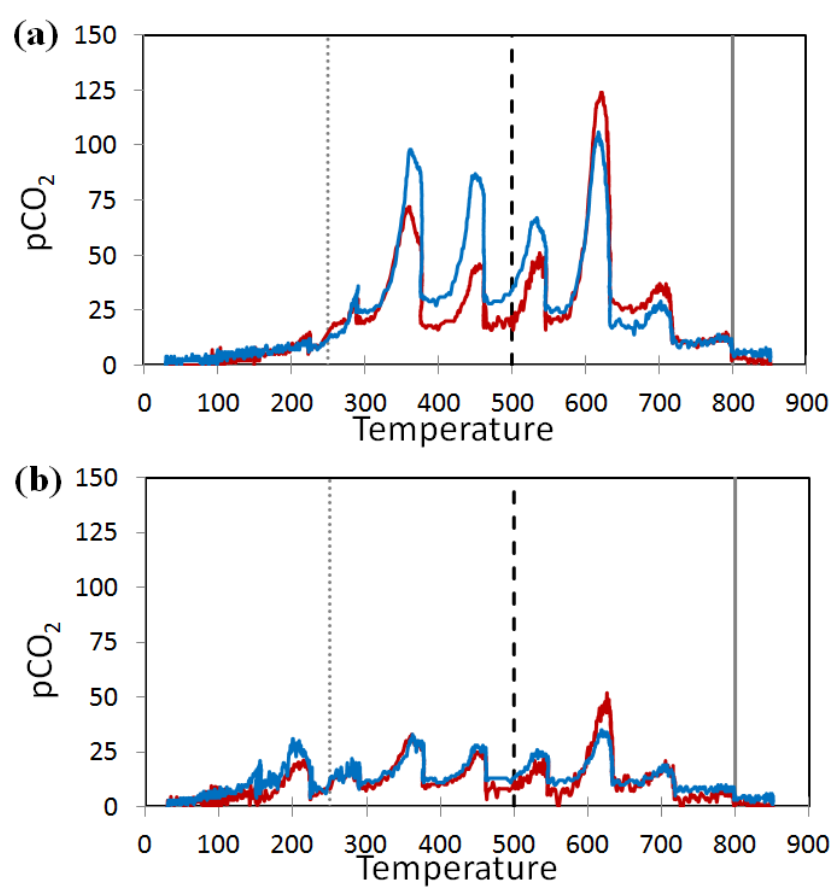

Figure 6. Thermograms ( $n=2$; blue and red lines) of phytoliths obtained from (a) durum wheat leaves, phytoliths extracted following protocol 1a (Table S2), and (b) soil phytoliths MSG70 extracted using a conventional protocol adapted to soil and sediment materials. Peaks are artifacts of the $100^{\circ} \mathrm{C}$ temperature-step increments. Vertical lines indicate main temperature thresholds, as explained in the text.

mogeneous and from a single source (atmospheric $\mathrm{CO}_{2}$ ), the ${ }^{14} \mathrm{C}$ results from all $\mathrm{CO}_{2}$ temperature-fractions should be in absolute agreement, as Fernandez et al. (2015) demonstrated by subjecting carbonaceous materials to ramp pyrolysis and subsequently measuring them by ${ }^{14} \mathrm{C}$-AMS.

\subsection{The SOM-derived C to phytC hypothesis set of evidence}

Results from both above- and below-ground experiments showed that the ${ }^{14} \mathrm{C}$ offsets between phytC and stems and leaves pointed toward the oldest SOM ${ }^{14} \mathrm{C}$ values (Figs. 2 and 4). This confirmed that a fraction of the old SOM-derived C occluded in phytoliths was more resistant (or less accessible) to oxidation than the occluded $\mathrm{C}$ derived from recent photosynthesis or from recent SOM. Once the most labile (or more accessible) $\mathrm{C}$ had been removed, the older and more resistant carbon fraction became dominant. This behavior mirrors that in a recent study showing an increase in ${ }^{14} \mathrm{C}$ age offsets of phytoliths with increasing combustion temperature (Yin et al., 2014), and also the thermal decomposability pattern illustrated in the phytC thermograms (Fig. 6).

Our findings also imply that a portion of SOM-derived C is absorbed by the roots, transferred to the stems and leaves, and finally occluded into phytoliths. In the bulk plant organs, 
the old SOM-derived C amount is far too small to be ${ }^{14} \mathrm{C}$ detected in tissue clippings, as it is masked by the large amounts of photosynthetic atmospheric carbon tissue (bulk stems and leaves averaged $\sim 41 \%$ carbon; Tables S1-S3). On the other hand, in phytoliths, the old SOM-derived $\mathrm{C}$ becomes overrepresented when the most labile-accessible phytC starts to be oxidized. It should be noted that the ${ }^{14} \mathrm{C}$ ages of the oldest SOM fraction are averaged bulk values that do not yield any precise assessment of the fine-scale ${ }^{14} \mathrm{C}$ age of the $\mathrm{C}$ that may have been absorbed. These drawbacks prevent precise quantification of the old SOM (probably diluted by the young SOM)-derived $\mathrm{C}$ contribution to phytC. The impossibility of quantifying precisely the amounts of soil $\mathrm{C}$ and associated ${ }^{14} \mathrm{C}$ signatures in phytC precludes application of any correction that would allow phytC to be used as a reliable dating material. As in any other heterogeneous carbon pool, the phytC continuum can be similarly partitioned differently by distinctive chemical extractions. For instance, in Piperno (2016) the entire data set of post-bomb Neotropical plant phytolith extracts were neither accurate nor precise. While ${ }^{14} \mathrm{C}$ offsets reached discrepancies as high as $4.4 \mathrm{kyr}$ between expected calendar ages and phytC, two pairs of phytolith extracts obtained by distinct chemical treatments (sulfuric vs. nitric) yielded a $50 \%$ reproducibility rate (Table 1 , Santos et al., 2016).

Recent 3-D x-ray microscopy and NanoSIMS measurements of a phytolith sample from the Durum Wheat Enriched $\mathrm{CO}_{2}$ experiment (TD-F-L/1a-CEREGE, Table S1) (Alexandre et al., 2015) suggested two locations for phytC: in micrometric internal cavities and within the silica network. Rapid opening of internal cavities during the dissolution process resulted in losses of phytC found in these locations, which is expected when phytoliths are subject to rapid oxidation. Conversely, phytC in the silica network is homogeneously distributed at the micrometric scale, and is less accessible to oxidation. These two pools of phytC may account for the heterogeneity of phytC accessibility to oxidation.

\subsection{Rebuttals to possible arguments against the SOM-derived C contribution to phytC hypothesis}

Our experiments and data set allow the rejection of several hypotheses for the "anomalously" old ${ }^{14} \mathrm{C}$ ages for phytC. First, bias due to exogenous $\mathrm{C}$ contamination during the phytolith extractions performed simultaneously by several laboratories and artifacts of errors in background corrections are highly unlikely. In these cases the ${ }^{14} \mathrm{C}$ offsets would trend in a single direction, rather than being both positive and negative (Figs. $2 \mathrm{~b}$ and 4). In addition, aliquots of $\mathrm{SiO}_{2}$ blank yielded ${ }^{14} \mathrm{C}$ values in close agreement with the expected results, giving no indication of the presence of unusual contaminants. Second, natural- or spectrometer-produced anomalous $\delta^{13} \mathrm{C}$ shifts of phytC were not observed here (Figs. 3 and 5) nor elsewhere (Santos et al., 2010, 2012b; Sullivan and Parr, 2013). Third, contributions of soil-respired $\mathrm{CO}_{2}$ to ma-

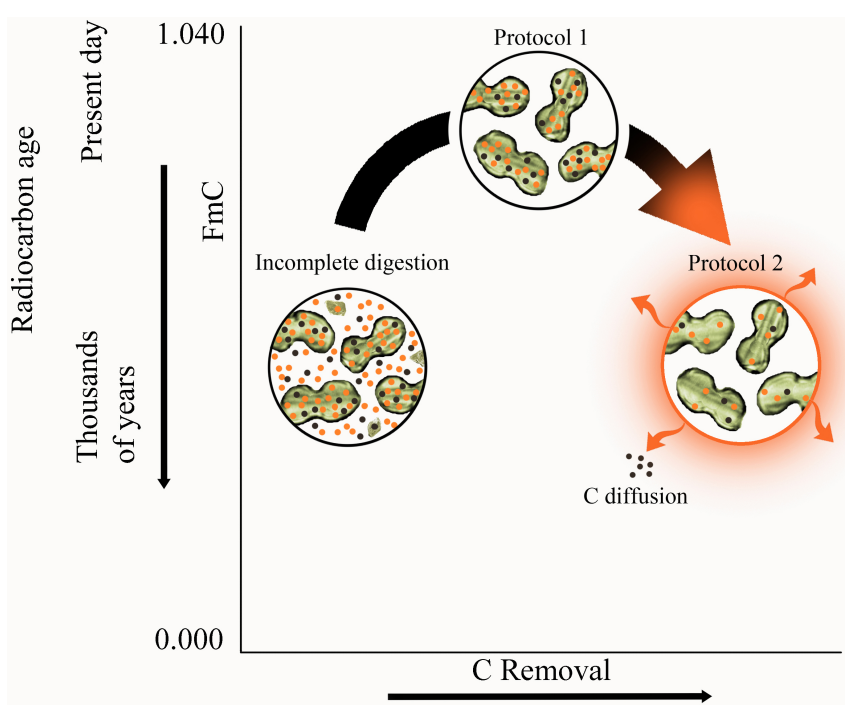

Figure 7. Conceptualization of the impact of phytolith extraction aggressiveness and $\mathrm{C}$ removal on ${ }^{14} \mathrm{C}$ age of phytoliths. Incomplete digestion leads to an accumulation of old residual $\mathrm{OM}$ in phytolith concentrates. Protocol 1 removes all OM residues and better preserves the dual source phytC signature. Protocol 2 removes all residual $\mathrm{OM}$ and labile (intrinsically young) phytC. For illustration purposes, young and old $\mathrm{C}$ are represented by black and orange dots, respectively (see Fig. 1b).

ture plant tissue (and phytC) were also negligible (Sect. 3.2). Fourth, phytC ${ }^{14} \mathrm{C}$ results were not biased by organic matter residues, as the efficiency of the phytolith extraction protocols was fully checked by SEM-EDS analyses (e.g., acceptance threshold of $\mathrm{C}: \mathrm{Si} \leq 0.1$ of 30 frames or more) (Corbineau et al., 2013), a method superior to microscopic evaluation alone (Figs. S1 and S2 in Supplement) (Kameník et al., 2013; Santos et al., 2012a). Moreover, our extracts were consistently reproducible regarding phytC yields across all labs involved (Tables S1-S3) and thermal decomposability properties (Fig. 6). Since it has been established that plants do not photosynthesize all carbon found within their tissues (details in Sect. 3.8), the uptake of SOM-derived C via the root system and its allocation to phytC is the only plausible explanation for the phytC ${ }^{14} \mathrm{C}$ offsets.

\subsection{Implications for the use of phytC as a proxy of plant $\mathrm{C}$}

Since plants (and more specifically phytoliths) contain a broad continuum of $\mathrm{C}$ with a complex mixture of chemical compounds of different turnover times as evidenced here (Figs. 2, 4, and 6), we believe that insufficient to excessive oxidations can result in wild moves in phytC ${ }^{14} \mathrm{C}$ dates from thousands, to hundreds, to back to thousands years old (Fig. 7).

While pure phytoliths produced from a less aggressive protocol (e.g., 1a) may minimize ${ }^{14} \mathrm{C}$ offsets to some de- 
gree, two factors remain that may explain the anomalous thousands of years old age of phytC indicated in the literature (Wilding, 1967; Kelly et al., 1991; McClaran and Umlauf, 2000; Santos et al., 2010, 2012a, 2016; Sullivan and Parr, 2013; Piperno, 2016). The first factor is the incomplete removal from phytolith concentrates of refractory SOM residues, either extraneous in the case of litter and soil samples or from the plant tissue itself. The accumulation effect of small quantities of residual recalcitrant (and somewhat older) SOM derived-C from concentrates due to incomplete digestion (Fig. 7), which can be detected via C:Si peaks with SEM-EDS (Corbineau et al., 2013), may be undetected under natural light microscopy. For instance, Santos et al. (2010) reported phytC ${ }^{14} \mathrm{C}$ age offsets of 2.3 to $8.5 \mathrm{kyr} \mathrm{BP}$ on phytolith concentrates extracted from living grasses using conventional digestion protocols, such as Kelly et al. (1991). Later, OM remnants in association with those anomalous ${ }^{14} \mathrm{C}$ results were detected by SEM-EDS in phytolith concentrates (Fig. 2 in Santos et al., 2012a), thus demonstrating that even very small amounts of particulate $\mathrm{C}$ were enough to bias the phytC ${ }^{14} \mathrm{C}$ results. Attempts to reproduce the atmospheric ${ }^{14} \mathrm{CO}_{2}$ bomb-peak in phytC from bamboo litter and mature leaves subjected to microwave digestions, also yielded offsets of several hundreds to $3.5 \mathrm{kyr}$ (Santos et al., 2012b; Sullivan and Parr, 2013). Similarly, a set of post-bomb Neotropical plant phytolith extracts produced by two protocols yielded phytC ${ }^{14} \mathrm{C}$ ages that were highly inaccurate, e.g., phytC ${ }^{14} \mathrm{C}$ offsets ranging from several decades to $4.4 \mathrm{kyr}$ (Santos et al., 2016). In those cases, preferential bias due to post-depositional occlusion of SOM was unlikely. All phytolith extracts analyzed were obtained from living or close to living vegetation, undergoing different extraction procedures coupled with optical microscope analyses (for purity evaluations). Cumulative effects of $\mathrm{OM}$ remnants on phytoliths would also explain the higher phytC yields (Kelly et al., 1991; Li et al., 2014; Parr and Sullivan, 2005; Santos et al., 2010; Song et al., 2014). The second factor is the increasing relative proportion of old SOM-derived $\mathrm{C}$ in phytC when phytolith extraction aggressiveness is high enough to remove the phytC fraction most sensitive to oxidation (e.g., the labile-accessible $\mathrm{C}$ fraction termed "protocol 2" in Fig. 7). Once carbon partitioning takes place via either further chemical extractions or increased combustion temperatures, phytC concentrations tend to drop followed by increased ${ }^{14} \mathrm{C}$ offsets to thousands of years old (Yin et al., 2014 and the present work).

Since the range of old SOM-derived C content in phytC left by a given protocol can be large (Fig. 2), and can vary in association to the abundances of $\mathrm{C}$ fractions within the substrates and their respective ${ }^{14} \mathrm{C}$ signatures (Fig. 4), any attempt to apply a systematic correction to obtain a phytC $\mathrm{Fm}^{14} \mathrm{C}$ signature derived solely from photosynthesis is likely to fail. We can also assume that when grasses are forced to reach greater rooting depths (Sivandran and Bras, 2012) than the ones sampled here, where the proportion of intrinsic- older organic compounds is likely to rise (Telles et al., 2003; Torn et al., 2009; Kleber, 2010; Petsch et al., 2001), old SOM-derived $\mathrm{C}$ in phytC and its $\mathrm{Fm}^{14} \mathrm{C}$ depletions would also increase. Furthermore, by themselves the ${ }^{14} \mathrm{C}$ signatures of phytC pools with competing ${ }^{14} \mathrm{C}$ ages (recent SOMderived $\mathrm{C}$ vs. present-day atmospheric ${ }^{14} \mathrm{CO}_{2}$ ) are insufficient to distinguish them. Therefore, the old soil $\mathrm{C}$ to phytC contributions found here in association with the ${ }^{14} \mathrm{C}$ signatures of phytoliths extracted from living grasses are likely to be only a very small fraction of the total SOM contribution to phytC, as discussed earlier.

Further work is still needed to assess the full impact of SOM (e.g., the different fractions of labile vs. recalcitrant carbon; Han et al., 2007) to the phytC pool. At natural conditions the presence of SOM-derived $\mathrm{C}$ in phytC may bias the $\delta^{13} \mathrm{C}$ signature to a lesser extent if the SOM and the plants of origin have similar photosynthetic pathways $\left(\mathrm{C}_{3}\right.$ or $\left.\mathrm{C}_{4}\right)$. The bias may however be significant if they are not. The $\delta^{13} \mathrm{C}$ signature of SOM can be hard to assess, especially in the case of phytoliths extracted from sedimentary archives. Thus, we suggest that the use of ${ }^{14} \mathrm{C}$ and $\delta^{13} \mathrm{C}$ signatures of phytC as a dating tool or as a proxy of plant or atmospheric $\mathrm{CO}_{2}$ signatures should be reappraised in the light of the present findings.

\subsection{Implications for long-term atmospheric $\mathrm{CO}_{2}$ biosequestration}

The evidence for a SOM-derived C contribution to phytC decreases the putative effectiveness of grasslands and crops to sequester atmospheric $\mathrm{CO}_{2}$ for two reasons. Besides negatively affecting phytolith $\mathrm{C}$ storage capacity, our findings most importantly invalidate phytC accumulation rates estimated from direct ${ }^{14} \mathrm{C}$ dating of soil phytoliths (Parr and Sullivan, 2005). In addition, other issues may also come into play. For instance, the phytolith biosequestration hypothesis is based essentially on the following premises. First, high phytC concentrations are required. Values of $1.5-3 \% \mathrm{dwt}$ have been quantified (e.g., Li et al., 2013; Parr and Sullivan, 2011; Parr et al., 2010). These values are more than 10 times higher than the concentrations recently measured by others $(<0.1 \% \mathrm{dwt}$, Santos et al., 2010). Differences in the efficiency of phytolith extraction protocols (Kameník et al., 2013), combined with the lack of proper control (blanks) and reproducibility of results (Corbineau et al., 2013) may have contributed to these high phytC concentrations. Second, a soil phytolith stability factor of 70 to $90 \%$ based on a few ${ }^{14} \mathrm{C}$ measurements of soil phytoliths (e.g., Parr and Sullivan, 2005) has been estimated and widely used (Li et al., 2014) regardless of soil type. These high percentage estimates differ from those of biogenic Si fluxes, based on Si pool measurements in tropical soil-plant systems. For instance, according to Alexandre et al. (2011) investigating two soil/plant systems in intertropical areas, only $10 \%$ of phytoliths produced annually are in fact preserved for extended periods, 
the remaining $90 \%$ being rapidly dissolved due to weathering (Oleschko et al., 2004). These proportions would reasonably depend on environmental conditions such as activity of elements $(\mathrm{Si}, \mathrm{Al}, \mathrm{Fe}, \mathrm{H}+)$ in soil solution, morphology of phytoliths (and thus vegetation type), and elemental concentration of phytoliths (and thus soil type).

Only as an exercise, we used the highest phytC yield measured in the frame of the present study $(0.3 \%$ of phytoliths) coupled with the $10 \%$ phytolith stability factor estimated from Alexandre et al. (2011), to recalculate a global grassland phytC-sink. We obtain a value of $4.1 \times 10^{4} \mathrm{tC} \mathrm{yr}^{-1}$, which is roughly one hundred times lower than the $3.7 \times 10^{6} \mathrm{tC} \mathrm{yr}^{-1}$ value reported elsewhere (Song et al., 2014 and references therein). This amount is insignificant when compared to the $2.6 \times 10^{9} \mathrm{tC} \mathrm{yr}^{-1}$ estimate for the land $\mathrm{C}$ sink (IPCC, 2007), or to the $0.4 \times 10^{9} \mathrm{tC} \mathrm{yr}^{-1}$ global mean long-term soil C accumulation rate (Schlesinger, 1990). This suggests that previous conclusions on the importance of developing silica accumulator crops for increasing atmospheric $\mathrm{C}$ sequestration should be reconsidered.

\subsection{Implications for our understanding of soil $\mathrm{C}$ pools mobilization}

Our findings have important implications for our understanding of the mobilization of soil C pools. Several studies have shown that terrestrial plant roots can uptake soil dissolved inorganic carbon (DIC). DIC can be transported directly by the transpiration stream or fixed in mycorrhizal and root tissues and subsequently translocated in the form of amino acid (Gioseffi et al., 2012; Rasmussen et al., 2010; Talbot and Treseder, 2010). DIC can represent 1-3\% of total leaf-fixed $\mathrm{CO}_{2}$ (Ford et al., 2007; Ubierna et al., 2009). However, as DIC is expected to be in equilibrium with soil $\mathrm{CO}_{2}$ respired from autotrophic and heterotrophic sources, its ${ }^{14} \mathrm{C}$ signature should reflect an average of SOM ${ }^{14} \mathrm{C}$ signatures, close to contemporary. Assuming soil DIC as the soil end-member in Fig. 2, the phytC samples from ambient $\mathrm{CO}_{2}$ experiments would plot along mixing lines with lower slopes than the actual ones. The ${ }^{14} \mathrm{C}$ age of several thousand years systematically measured for the most resistant phytC, rather suggests that an older SOM fraction supplies the SOM-derived C absorbed by the roots, up-taken and transported to the stem and leaves tissues.

The fact that roots can also acquire soil $\mathrm{C}$ in a molecular form has been previously inferred from the detection in roots, stems and shoots of polycyclic aromatic hydrocarbons (PAH) (Gao et al., 2010; Yu et al., 2013), and soil amino acids (AA) (Paungfoo-Lonhienne et al., 2008; Warren, 2012; Whiteside et al., 2009, 2012). Although reported PAH concentrations were three orders of magnitude below phytC concentrations (e.g., $10^{-9} \mathrm{~g} \mathrm{~g}^{-1}$ vs. $10^{-6} \mathrm{~g} \mathrm{~g}^{-1}$, assuming $0.1 \% \mathrm{dwt}$ for both phytolith concentration in plants and phytC content in phytoliths), AAs make up several tenths of a percent of the plant nitrogen requirements (Lipson and Näsholm, 2001).
Arbuscular mycorrhizal fungi, which colonize $70 \%$ of plant families (Talbot and Treseder, 2010; Treseder and Turner, 2007) are probably at the base of the transfer of molecular $\mathrm{C}$ from the rhizosphere to the roots, although intact protein has also been shown to enter root cells without the help of mycorrhizae, most likely via endocytosis (Paungfoo-Lonhienne et al., 2008). At lower scales, AA transporters were shown to confer the ability of plants to absorb molecular $\mathrm{C}$ from the soil solution (Lipson and Näsholm, 2001; Tegeder, 2012). Root acquisition of humic substances (active and passive) and its positive effect on plant nutrient uptake has been also reported (Trevisan et al., 2010). The incorporation of belowground physical, chemical and biological processes in the rhizosphere (e.g., microbial priming effect or $\mathrm{N}$ and $\mathrm{C}$ cycle interactions) have also been proposed (Heimann and Reichstein, 2008 and references therein). The results of the present study go a step further by demonstrating that part of the soil molecular $\mathrm{C}$ absorbed by roots is several thousand years old. Recent studies also show that old, supposedly poorly accessible SOM (Kleber, 2010; Petsch et al., 2001; Schmidt et al., 2011), can be decomposed by organisms or catalytic enzymes (Dungait et al., 2012; Marín-Spiotta et al., 2014). Common sources of dissolved $\mathrm{Si}$ for plants are clay minerals and amorphous silicates (allophane, imogolite). Due to their small size, high surface functional groups, area, and porosity, these minerals stabilize SOM either by adsorption onto their surface or by aggregation (Basile-Doelsch et al., 2007; Jones and Singh, 2014; Kögel-Knabner et al., 2010). Further studies are needed to investigate whether dissolution of Si-bearing forms during active uptake of $\mathrm{Si}$ (Ma et al., 2006) may also promote old SOM mobilization, ready to be chelated with $\mathrm{Si}$, absorbed by the roots and translocated to the stems and leaves.

\section{Conclusions}

Although photosynthesis is the main source of $\mathrm{C}$ in plant tissue, we have demonstrated here that grass biosilica (phytoliths) occlude SOM-derived C that can be several thousand years old, debunking the common assumption of phytC photosynthetic carbon exclusivity. This finding suggests causes for previous anomalously older phytC ${ }^{14} \mathrm{C}$ ages found in the literature. Moreover, the fact that phytC is not uniquely constituted of photosynthetic $\mathrm{C}$ limits the usefulness of phytC either as a dating tool or as a significant sink of atmospheric $\mathrm{CO}_{2}$. Revised estimates of atmospheric $\mathrm{CO}_{2}$ biosequestration by phytoliths led to values that are insignificant compared to the total land $\mathrm{C}$ or soil C sinks. All in all, by demonstrating that old SOM-derived $\mathrm{C}$ is accessible to roots and builds up in plant biosilica, this study constitutes a basis to further investigate the mechanism and amplitude of old SOM recycling by roots for a better understanding of the $\mathrm{C}$ cycle at the soil/plant interface. 


\section{The Supplement related to this article is available online at doi:10.5194/bg-13-1269-2016-supplement.}

Author contributions. G. M. Santos conceived the study. G. M. Santos, A. Alexandre, P. E. Reyerson, and R. Corbineau designed the experiments and conceived the strategies for phytolith extraction and purity analyses. G. M. Santos, P. E. Reyerson, A. Alexandre, A. Harutyunyan, R. Corbineau and $\mathrm{H}$. Martinez De La Torre performed the experiments and contributed to analysis tools. F. Badeck and L. Cattivelli provided bulk tissue and soil samples from T. Durum FACE. G. M. Santos, A. Alexandre, and P. E. Reyerson interpreted the data and wrote the paper. All authors discussed the results and implications, and commented on the paper.

Acknowledgements. The authors gratefully acknowledge the support of the US National Science Foundation (DEB-1144888 to GMS), the French FIR 2010 (Aix-Marseille Université), ECCOREV 2011, AIR Archéométrie 2011(CNRS) and Labex OT-Med 2013. PER wishes to thank J. A. Mason (University of Wisconsin-Madison) and the National Lacustrine Core Facility (University of Minnesota) for lab space usage. GMS thanks M. J. Ottman, B. Kimball, S. W. Leavitt, E. Pendall, P. Pinter, G. Hendrey, H. L. Cho and R. Rauschkolb for providing the archived Maricopa FACE samples. Financial support provided by the Durum experiment via the "Fondazione in rete per la ricerca agroalimentare" with the AGER program: agroalimentare e ricerca is gratefully acknowledged. We thank J. Southon for help with the ${ }^{14} \mathrm{C}$-AMS analyses, and C. Czimczik and M. Lupasco for technical support with the $\mathrm{CO}_{2}$ flux measurements, help in interpreting the data, and suggestions and comments on an early version of this paper. We would like to thank $\mathrm{X}$. Xu for the stable isotope analysis and technical support for $\mathrm{CO}_{2}$-air cryogenic extraction, and Q. Lin and the Laboratory for Electron and X-ray Instrumentation (LEXI) at UC Irvine for access to lab space and assistance with X-ray analytical techniques. We also thank S. Fahrni for providing the inorganic fertilizer used in the control planter, and K. Gallagher for her efforts on the estimates of percent carbon of some amendments. A. Alexandre thanks J. Balesdent (CEREGE) for helpful discussion on root absorption of molecular C. The authors also wish to extend their thanks to the Editor Roland Bol and the three anonymous reviewers for the constructive comments.

Edited by: R. Bol

\section{References}

Alexandre, A., Bouvet, M., and Abbadie, L.: The role of savannas in the terrestrial Si cycle: A case-study from Lamto, Ivory Coast, Glob. Planet. Change, 78, 162-169, 2011.

Alexandre, A., Basile-Doelsch, I., Delhaye, T., Borshneck, D., Mazur, J. C., Reyerson, P., and Santos, G. M.: New highlights of phytolith structure and occluded carbon location: 3-D X-ray microscopy and NanoSIMS results, Biogeosciences, 12, 863-873, doi:10.5194/bg-12-863-2015, 2015.
Badeck, F. W., Rizza, F., Maré, C., Cattivelli, A., Zaldei, F., and Miglietta, F.: Durum wheat growth under elevated $\mathrm{CO}_{2}$ : first results of a FACE experiment, in: Proceedings of the XVI National Congress of Agrometeorology: Agrometeorology for Environmental and Food Security, Bologna, Pàtron Editore, 2012.

Bae, M.-S., Schauer, J. J., Deminter, J. T., Turner, J. R., Smith, D., Cary, and R. A.: Validation of a semi-continuous instrument for elemental carbon and organic carbon using a thermal-optical method, Atmos. Environ., 38, 2885-2893, 2004.

Basile-Doelsch, I., Amundson, R., Stone, W. E. E., Borschneck, D., Bottero, J. Y., Moustier, S., Masin, F., and Colin, F.: Mineral control of carbon pools in a volcanic soil horizon, Geoderma, 137, 477-489, 2007.

Bauer, P., Elbaum, R., and Weiss, I. M.: Calcium and silicon mineralization in land plants: Transport, structure and function, Plant Sci., 180, 746-756, 2011.

Beverly, R., Beaumont, W., Tauz, D., Ormsby, K., Von Reden, K., Santos, G. M., and Southon, J. R.: The Keck Carbon Cycle AMS Laboratory, University of California Irvine: status report, Radiocarbon, 52, 301-309, 2010.

Carter, J. A.: Atmospheric carbon isotope signatures in phytolithoccluded carbon, Quaternary Internat., 193, 20-29, 2009.

Cheng, P., Zhou, W., Wang, H., Lu, X., and Du, H.: ${ }^{14} \mathrm{C}$ dating of soil organic carbon (SOC) in loess-paleosol using sequential pyrolysis and accelerator mass spectrometry (AMS), Radiocarbon, 55, 563-570, 2013.

Corbineau, R., Reyerson, P. E., Alexandre, A., and Santos, G. M.: Towards producing pure phytolith concentrates from plants that are suitable for carbon isotopic analysis, Rev. Palaeobot. Palynol., 197, 179-185, 2013.

Crespin, J., Alexandre, A., Sylvestre, F., Sonzogni, C., Pailles, C., and Garreta, V.: IR laser extraction technique applied to oxygen isotope analysis of small biogenic silica samples, Ann. Chem., 80, 2372-2378, 2008.

Czimzik, C. I., Trumbore, S. E., Carbone, M. S., and Winston, G. C.: Changing sources of soil respiration with time since fire in a boreal forest, Glob. Change Biol., 12, 957-971, 2006.

Deer, W. A., Howie, R. A., and Zussman, J.: An introduction to the rock-forming minerals, Essex, Longman Scientific and Technical, 2nd Edn., Longman Scientific and Technical, Essex, 696 pp., 1992.

Dungait, J. A., Hopkins, D. W., Gregory, A. S., and Whitmore, A. P.: Soil organic matter turnover is governed by accessibility not recalcitrance, Glob. Change Biol., 18, 1781-1796, 2012.

Fernandez, A., Santos, G. M., Williams, E. K., Pendergraft, M. A., Vetter, L., and Rosenheim, B. E.: Blank corrections for ramped pyrolysis radiocarbon dating of sedimentary and soil organic carbon, Anal. Chem., 86, 12085-12092, 2014.

Ford, C. R., Wurzburger, N., Hendrick, R. L., and Teskey, R. O.: Soil DIC uptake and fixation in Pinus taeda seedlings and its $\mathrm{C}$ contribution to plant tissues and ectomycorrhizal fungi, Tree Physiol., 27, 375-383, 2007.

Gao, Y., Cheng, Z., Ling, W., and Huang, J.: Arbuscular mycorrhizal fungal hyphae contribute to the uptake of polycyclic aromatic hydrocarbons by plant roots, Bioresour. Technol., 101, 6895-6901, 2010.

Geis, J. W.: Biogenic silica in selected species of deciduous angiosperms, Soil Sci., 116, 113-130, 1973. 
Gioseffi, E., de Neergaard, A., and Schjoerring, J. K.: Interactions between uptake of amino acids and inorganic nitrogen in wheat plants, Biogeosciences, 9, 1509-1518, doi:10.5194/bg-9-15092012, 2012.

Han, Y., Cao, J., An, Z., Chow, J. C., Watson, J. G., Jin, Z., Fung, K., and Liu, S.: Evaluation of the thermal/optical reflectance method for quantification of elemental carbon in sediments, Chemosphere, 69, 526-533, 2007.

Harvey, O. R., Kuo, L. J., Zimmerman, A. R., Louchouarn, P., Amonette, J. E., and Herbert, B. E.: An Index-Based Approach to Assessing Recalcitrance and Soil Carbon Sequestration Potential of Engineered Black Carbons (Biochars), Environ. Sci. Technol., 46, 1415-1421, 2012.

Heimann, M. and Reichstein, M.: Terrestrial ecosystem carbon dynamics and climate feedbacks, Nature, 451, 289-292, 2008.

Hibberd, J. M. and Quick, W. P.: Characteristics of $\mathrm{C}_{4}$ photosynthesis in stems and petioles of $\mathrm{C}_{3}$ flowering plants. Nature, 415 , 451-454, 2002.

IPCC: Climate Change 2007: Synthesis Report. Contribution of Working Groups I, II and III to the Fourth Assessment Report of the Intergovernmental Panel on Climate Change, Geneva, Switzerland, 2007.

Jones, E. and Singh, B.: Organo-mineral interactions in contrasting soils under natural vegetation, Front. Environ. Sci., 2, 1-5, 2014.

Kameník, J., Mizera, J., and Řanda, Z.: Chemical composition of plant silica phytoliths, Environ. Chem. Lett., 11, 189-195, 2013.

Kelly, E. F., Amundson, R. G., Marino, B. D., and Deniro, M. J.: Stable isotope ratios of carbon in phytoliths as a quantitative method of monitoring vegetation and climate change, Quaternary Res., 35, 222-233, 1991.

Kleber, M.: What is recalcitrant soil organic matter?, Environ. Chem., 7, 320-332, 2010.

Kögel-Knabner, I., Amelung, W., Cao, Z., Fiedler, S., Frenzel, P., Jahn, R., Kalbitz, K., Kölbl, A., and Schloter, M.: Biogeochemistry of paddy soils. Geoderma, 157, 1-14, 2010.

Leavitt, S. W.: Carbon isotope dynamics of $\mathrm{CO}_{2}$-enriched FACE cotton and soils, Agricul. Forest Meteorol., 70, 87-101, 1994.

Leavitt, S. W., Pendall, E., Paul, E. A., Brooks, T., Kimball, B. A., Pinter, P. J., Johnson, B., Matthias, A., Wall, G. W., and LaMorte, R. L.: Stable-carbon isotopes and soil organic carbon in wheat under $\mathrm{CO}_{2}$ enrichment, New Phytol., 150, 305-314, 2001.

Levin, I.: Twenty Years of Atmospheric $\mathrm{CO}_{2}$ Observations At Schauinsland Station, Germany, Radiocarbon, 39, 205-218, 1997.

Levin, I., Kromer, B., and Hammer, S.: Atmospheric $\Delta^{14} \mathrm{CO}_{2}$ trend in Western European background air from 2000 to 2012, Tellus B, 65, 20092, doi:10.3402/tellusb.v65i0.20092, 2013.

Li, B., Song, Z., Li, Z., Wang, H., Gui, R., and Song, R.: Phylogenetic variation of phytolith carbon sequestration in bamboos, Sci. Rep., 4, doi:10.1038/srep04710, 2014.

Li, Z., Song, Z., Parr, J. F., and Wang, H.: Occluded C in rice phytoliths: implications to biogeochemical carbon sequestration, Plant Soil, 370, 615-623, 2013.

Lipson, D. and Näsholm, T.: The unexpected versatility of plants: organic nitrogen use and availability in terrestrial ecosystems, Oecologia, 128, 305-316, 2001.

Ma, J. F., Tamai, K., Yamaji, N., Mitani, N., Konishi, S., Katsuhara, M., Ishiguro, M., Murata, Y., and Yano, M.: A silicon transporter in rice, Nature, 44, 688-691, 2006.
Marín-Spiotta, E., Gruley, K. E., Crawford, J., Atkinson, E. E., Miesel, J. R., Greene, S., Cardona-Correa, C., and Spencer, R. G. M.: Paradigm shifts in soil organic matter research affect interpretations of aquatic carbon cycling: transcending disciplinary and ecosystem boundaries, Biogeochemistry, 117, 279297, 2014.

Mcclaran, M. P. and Umlauf, M.: Desert Grassland Dynamics Estimated from Carbon Isotopes in Grass Phytoliths and Soil Organic Matter, J. Vegetat. Sci., 11, 71-76, 2000.

Mcinerney, F. A., Strömberg, C. A. E., and White, J. C.: The Neogene transition from C3 to C4 grasslands in North America: stable isotope ratios of fossil phytoliths, Paleobiology, 37, 23-49, 2011.

Nardi, S., Pizzeghello, D., Muscolo, A., and Vianello, A.: Physiological effects of humic substances on higher plants,Soil Biol. Biochem., 34, 1527-1536, 2002.

Oleschko, K., Parrot, J. F., Ronquillo, G., Shoba, S., Stoops, G., and Marcelino, V.: Weathering: toward a fractal quantifying, Mathemat. Geol., 36, 607-627, 2004.

Ottman, M. J., Kimball, B. A., Pinter, P. J., Wall, G. W., Vanderlip, R. L., Leavitt, S. W., LaMorte, R. L., Matthias, A. D., and Brooks, T. J.: Elevated $\mathrm{CO}_{2}$ increases sorghum biomass under drought conditions, New Phytol., 150, 261-273, 2001.

Parr, J. F. and Sullivan, L. A.: Soil carbon sequestration in phytoliths, Soil Biol. Biochem., 37, 117-124, 2005.

Parr, J. F. and Sullivan, L. A.: Phytolith occluded carbon and silica variability in wheat cultivars, Plant Soil, 342, 165-171, 2011.

Parr, J., Sullivan, L., and Quirk, R.: Sugarcane phytoliths: Encapsulation and sequestration of a long-lived carbon fraction, Sugar Tech., 11, 17-21, 2009.

Parr, J., Sullivan, L., Chen, B., and Zheng, W.: Carbon biosequestration within the phytoliths of economic bamboo species, Glob. Change Biol., 16, 2661-2667, 2010.

Paungfoo-Lonhienne, C., Lonhienne, T. G., Rentsch, D., Robinson, N., Christie, M., Webb, R. I., Gamage, H. K. Carroll, B. J., Schenk, P. M., and Schmidt, S.: Plants can use protein as a nitrogen source without assistance from other organisms, Proc. Natl. Acad. Sci., 105, 4524-4529, 2008.

Pausch, J. and Kuzyakov, Y.: Photoassimilate allocation and dynamics of hotspots in roots visualized by ${ }^{14} \mathrm{C}$ phosphor imaging, $\mathrm{J}$. Plant Nutr. Soil Sci., 174, 12-19, 2011.

Petsch, S. T., Eglinton, T. I., and Edwards, K. J.: ${ }^{14}$ C-dead living biomass: evidence for microbial assimilation of ancient organic carbon during shale weathering, Science, 292, 1127-1131, 2001.

Piperno, D. R.: Phytoliths: a comprehensive guide for archaeologists and paleoecologists, Lanham, MD, AltaMira Press, 304 pp., 2006.

Piperno, D. R.: Phytolith radiocarbon dating in archaeological and paleoecological research: a case study of phytoliths from modern Neotropical plants and a review of the previous dating evidence, J. Archaeol. Sci., in press, doi:10.1016/j.jas.2015.06.002, 2016.

Piperno, D. R. and Stothert, K. E.: Phytolith evidence for early Holocene Cucurbita domestication in southwest Ecuador, Science, 299, 1054-1057, 2003.

Plante, A. F., Pernes, M., and Chenu, C.: Changes in clay-associated organic matter quality in a $\mathrm{C}$ depletion sequence as measured by differential thermal analyses, Geoderma, 129, 186-199, 2005.

Plante, A. F., Fernández, J. M., Haddix, M. L., Steinweg, J. M., and Conant, R. T.: Biological, chemical and thermal indices of 
soil organic matter stability in four grassland soils, Soil Biol. Biochem., 43, 1051-1058, 2011.

Plante, A. F., Beaupré, S. R., Roberts, M. L., and Baisden, T.: Distribution of Radiocarbon Ages in Soil Organic Matter by Thermal Fractionation, Radiocarbon, 55, 1077-1083, 2013.

Raich, J. W. and Sclesinger, W. H.: The global carbon dioxide flux in soil respiration and its relationship to vegetation and climate, Tellus B, 44, 81-99, 1992.

Rasmussen, J., Sauheitl, L., Eriksen, J., and Kuzyakov, Y.: Plant uptake of dual-labeled organic $\mathrm{N}$ biased by inorganic $\mathrm{C}$ uptake: Results of a triple labeling study, Soil Biol. Biochem., 42, 524$527,2010$.

Raven, J. A.: Cycling Silicon: The Role of Accumulation in Plants, New Phytol., 158, 419-421, 2003.

Rosenheim, B. E., Santoro, J. A., Gunter, M., and Domack, E. W.: Improving Antarctic sediment C-14 dating using ramped pyrolysis: an example from the Hugo Island Trough, Radiocarbon, 55, 115-126, 2013.

Runge, F.: The opal phytolith inventory of soils in central Africa - Quantities, shapes, classification, and spectra, Revi. Palaeobot. Palynol., 107, 23-53, 1999.

Santos, G. M. and Ormsby, K.: Behavioral variability in ABA chemical pretreatment close to the ${ }^{14} \mathrm{C}$ age limit, Radiocarbon, 55, 534-544, 2013.

Santos, G. M., Southon, J. R., Druffel-Rodriguez, K. C., Griffin, S., and Mazon, M.: Magnesium perchlorate as an alternative water trap in AMS graphite sample preparation: A report on sample preparation at KCCAMS at the University of California, Irvine, Radiocarbon, 46, 165-173, 2004.

Santos, G. M., Moore, R. B., Southon, J. R., Griffin, S., Hinger, E., and Zhang, D.: Ultra small-mass ${ }^{14} \mathrm{C}$-AMS sample preparation and analysis at the KCCAMS Faclitity, Nuclear Instruments and Methods in Physics Research B, 259, 293-302, 2007.

Santos, G. M., Alexandre, A., Coe, H. H., Reyerson, P. E., Southon, J. R., and De Carvalho, C. N.: The phytolith ${ }^{14}$ C puzzle: a tale of background determinations and accuracy tests, Radiocarbon, 52, 113-128, 2010.

Santos, G. M., Alexandre, A., Southon, J. R., Treseder, K. K., Corbineau, R., and Reyerson, P. E.: Possible source of ancient carbon in phytolith concentrates from harvested grasses, Biogeosciences, 9, 1873-1884, doi:10.5194/bg-9-1873-2012, 2012a.

Santos, G. M., Southon, J. R., Alexandre, A., Corbineau, R., and Reyerson, P. E.: Interactive comment on "Comment on: "Possible source of ancient carbon in phytolith concentrates from harvested grasses" by G. M. Santos et al. (2012)" by L. A. Sullivan and J. F. Parr., Biogeosci. Discuss., 9, C6114-C6124, 2012 b.

Santos, G. M., Alexandre, A., and Prior, C. A.: From radiocarbon analysis to interpretation: A comment on "Phytolith Radiocarbon Dating in Archaeological and Paleoecological Research: A Case Study of Phytoliths from Modern Neotropical Plants and a Review of the Previous Dating Evidence", Journal of Archaeological Science (2016), doi:10.1016/j.jas.2015.06.002, by Dolores R. Piperno, J. Archaeol. Sci., in press, doi:10.1016/j.jas.2015.11.012, 2016.

Schlesinger, W. H.: Evidence from chronosequence studies for a low carbon-storage potential of soils, Nature, 348, 232-234, 1990.

Schmidt, M. W., Torn, M. S., Abiven, S., Dittmar, T., Guggenberger, G., Janssens, I. A., Kleber, M., and Trumbore, S. E.: Persistence of soil organic matter as an ecosystem property, Nature, 478, 4956, 2011.

Schrumpf, M., Kaiser, K., Guggenberger, G., Persson, T., KögelKnabner, I., and Schulze, E.-D.: Storage and stability of organic carbon in soils as related to depth, occlusion within aggregates, and attachment to minerals, Biogeosciences, 10, 16751691, doi:10.5194/bg-10-1675-2013, 2013.

Sivandran, G. and Bras, R. L.: Identifying the optimal spatially and temporally invariant root distribution for a semiarid environment, Water Resour. Res., 48, W12525, doi:10.1029/2012wr012055, 2012.

Smith, F. A. and White, J. W. C.: Modern calibration of phytolith carbon isotope signatures for $\mathrm{C} 3 / \mathrm{C} 4$ paleograssland reconstruction, Palaeogeogr. Palaeoclimatol., 207, 277-304, 2004.

Song, Z., Parr, J. F., and Guo, F.: Potential of global cropland phytolith carbon sink from optimization of cropping system and fertilization, PLOS One, 8, e73747, doi:10.1371/journal.pone.0073747, 2013.

Song, Z., Wang, H., Strong, P. J., and Guo, F.: Phytolith carbon sequestration in China's croplands, Eur. J. Agron., 53, 10-15, 2014.

Stuiver, M and Polach, H.: Reporting of ${ }^{14} \mathrm{C}$ data, Radiocarbon, 19, 355-363, 1977.

Sullivan, L. A. and Parr, J. F.: Comment on "Possible source of ancient carbon in phytolith concentrates from harvested grasses" by G. M. Santos et al. (2012), Biogeosciences, 10, 977-980, doi:10.5194/bg-10-977-2013, 2013.

Suttie, J. M., Reynolds, S. G., and Batello, C.: Grasslands of the World (FAO, 2005), 2005.

Talbot, J. M. and Treseder, K. K.: Controls of mycorrhizal uptake of organic nitrogen, Pedobiologia, 53, 169-179, 2010.

Tegeder, M.: Transporters for amino acids in plant cells: some functions and many unknowns, Curr. Opin. Plant Biol., 15, 315-321, 2012.

Telles, E. C. C., Camargo, P. B., Martinelli, L. A., Trumbore, S. E., Costa, E. S., Santos, J., Higuchi, N., and Oliveira Jr., R. C.: Influence of soil texture on carbon dynamics and storage potential in tropical forest soils of Amazonia, Global Biogeochem. Cy., 17, 1040, doi:10.1029/2002GB001953, 2003.

Toma, Y., Clifton-Brown, J., Sugiyama, S., Nakaboh, M., Hatano, R., Fernández, F. G., Stewart, J. R., Nishiwaki, A., and Yamada T.: Soil carbon stocks and carbon sequestration rates in seminatural grassland in Aso region, Kumamoto, Southern Japan, Glob. Change Biol., 19, 1676-1687, 2013.

Torn, M. S., Swanston, C. W., Castanha, C., and Trumbore, S. E.: Storage and turnover of organic matter in soil, in: Biophysicochemical Processes Involving Natural Nonliving Organic Matter in Environmental Systems, edited by: Senesi, N., Xing, B., and Huang, P. M., International. Union of Pure and Applied Chemistry (IUPAC), New York, NY, 219-272, 2009.

Treseder, K. K. and Turner, K. M.: Glomalin in ecosystems, Soil Sci. Soc. Am. J., 71, 1257-1266, 2007.

Trevisan, S., Francioso, O., Quaggiotti, S., and Nardi, S.: Humic substances biological activity at the plant-soil interface, Plant Signaling Behavior, 5, 635-643, 2010.

Ubierna, N., Marshall, J. D., and Cernusak, L. A.: A new method to measure carbon isotope composition of $\mathrm{CO}_{2}$ respired by trees: stem $\mathrm{CO}_{2}$ equilibration, Funct. Ecol., 23, 1050-1058, 2009. 
Warren, C. R.: Post-uptake metabolism affects quantification of amino acid uptake, New Phytol., 193, 522-531, 2012

Webb, E. A. and Longstaffe, F. J.: The oxygen isotopic compositions of silica phytoliths and plant water in grasses: Implications for the study of paleoclimate, Geochim. Cosmochim. Ac., 64, 767-780, 2000.

Webb, E. A. and Longstaffe, F. J.: Limitations on the climatic and ecological signals provided by the $\delta^{13} \mathrm{C}$ values of phytoliths from a C4 North American prairie grass, Geochim. Cosmochim. Ac., 74, 3041-3050, 2010.

Whiteside, M. D., Digman, M. A., Gratton, E., and Treseder, K. K.: Organic nitrogen uptake by arbuscular mycorrhizal fungi in a boreal forest, Soil Biol. Biochem., 55, 7-13, 2012.

Whiteside, M. D., Treseder, K. K., and Atsatt, P. R.: The brighter side of soils: quantum dots track organic nitrogen through fungi and plants, Ecology, 90, 100-108, 2009.

Wichern, F., Andreeva, D., Joergensen, R. G., and Kuzyakov, Y.: Stem labeling results in different patterns of ${ }^{14} \mathrm{C}$ rhizorespiration and ${ }^{15} \mathrm{~N}$ distribution in plants compared to natural assimilation pathways, J. Plant Nutr. Soil Sci., 174, 732-741, 2011.
Wilding, L. P.: Radiocarbon dating of biogenetic opal, Science, 156, 66-67, 1967.

Wu, Y., Yang, Y., Wang, H., and Wang, C.: The effects of chemical composition and distribution on the preservation of phytolith morphology, Appl. Phys. A, 114, 503-507, 2014.

Xu, X., Trumbore, S. E., Zheng, S., Southon, J. R., McDuffee, K. E., Luttgen, M., and Liu, J. C.: Modifying a sealed tube zinc reduction method for preparation of AMS graphite targets: Reducing background and attaining high precision, Nucl. Instrum. Methods B, 259, 320-329, 2007.

Yin, J., Yang, X., and Zheng, Y.: Influence of increasing combustion temperature on the AMS ${ }^{14} \mathrm{C}$ dating of modern crop phytoliths, Sci. Rep., 4, 6511, doi:10.1038/srep06511, 2014

Yu, W., Kuang, S., and Zhao, L.: Uptake, accumulation and translocation of polycyclic aromatic hydrocarbons by winter wheat cultured on oily sludge-amended soil, Chinese J. Geochem., 32, 295-302, 2013. 